Research Article

\title{
Thermal Performance Improvement of Solar Parabolic Dish System Using Modified Spiral Coil Tubular Receiver
}

\author{
Rajkumar Malviya $\mathbb{D}^{1},{ }^{1}$ Prashant V. Baredar $\mathbb{D}^{1},{ }^{1}$ and Anil Kumar $\mathbb{D}^{2,3}$ \\ ${ }^{1}$ Energy Centre, Maulana Azad National Institute of Technology, Bhopal, 462003 M.P., India \\ ${ }^{2}$ Department of Mechanical Engineering, Delhi Technological University, Delhi 110042, India \\ ${ }^{3}$ Centre for Energy and Environment, Delhi Technological University, Delhi 110042, India
}

Correspondence should be addressed to Rajkumar Malviya; er.rajkmalviya@gmail.com

Received 5 October 2021; Accepted 17 November 2021; Published 30 December 2021

Academic Editor: Alberto Álvarez-Gallegos

Copyright (c) 2021 Rajkumar Malviya et al. This is an open access article distributed under the Creative Commons Attribution License, which permits unrestricted use, distribution, and reproduction in any medium, provided the original work is properly cited.

\begin{abstract}
The present research intends to design an efficient receiver for solar thermal applications with a solar dish concentrator system. Thermal and dynamic analysis is carried out for different convolutions of a spiral coil, and experiments are performed for testing the modified absorber. Experimental results are validated for the spiral absorber with numerical results. Three receivers of different numbers of convolutions are analyzed, and simulation steps are performed for these receivers to make improvements in the system efficiency. Finally, 5 convolutions of a spiral coil tubular absorber are taken for the modified design of the system. Absorber position for every spiral convolution is kept at the focus of the concentrated solar dish collector to achieve maximum efficiency. Material used for the reflective surface is anodized aluminum and copper for the absorber. The diameter of the aperture for the parabolic dish collector is $1.4 \mathrm{~m}$. The maximum absorber temperature for May month comes out to be $296^{\circ} \mathrm{C}$, and the maximum working fluid outlet temperature is found to be $294.2^{\circ} \mathrm{C}$ which is near to simulating temperature of $289.59^{\circ} \mathrm{C}$ and $288.15^{\circ} \mathrm{C}$, respectively. This innovative design of the absorber consists of a feature of a $5 \mathrm{~mm}$ extension to the spiral tube at the exit and entry; hence, the turbulence effect could be overcome. Experimental thermal efficiency was found the highest (i.e., $\left.\eta_{\mathrm{th}}(\max )=75.98 \%\right)$ for May. This work emphasizes on improving thermal performance by obtaining optimum absorber size using convolution strategy. Investigation of 5 convolutions of spiral coil tubular absorber with extended ends for obtaining optimum performance than existing work is the superiority of this work.
\end{abstract}

\section{Introduction}

Solar thermal receiver (i.e., solar absorber) is the vital component in solar dish concentrator technologies. It behaves as a connecting linkage for the insolation and the heat transfer working fluid (HTWF) flowing in the absorber. HTWF transfers the heat to the system that would be further transformed for a usable form of energy. The three most important points related to thermal absorber have to keep in mind. First, the power of absorbing the solar radiant heat with minimum heat losses is the most important characteristic of a receiver. Second, the optical properties and the structural parameters related to the thermal absorber. Third, the role of conductive, convective, and radiation heat losses from the concentrator and receiver system. To discover a cost-effective receiver for a solar thermal PD system with improved performance is great anxiety for researchers.

There are various geometries of receivers, i.e., cylindrical, conical, and spherical. Apart from it, many other geometries are also there, which can be studied. Spiral coil absorber, cylindrical tube receiver, modified cavity monotube boiler receiver, conical cavity spiral receiver, cylindrical shape spiral coil receiver, all-glass evacuated tube receiver, etc., are the most used receivers nowadays. Many researchers work on the heat losses and the different shapes of the thermal absorber [1]. Scientists always underestimate the role of absorber shape in reducing heat losses. Absorber size should be as small as possible for reducing heat losses in a thermal system. Daabo et al. [2] compared optical and thermodynamic behavior of three receiver geometries, i.e., conical, 
cylindrical, and spherical. The capacity of conical shape absorber to receive and absorb the highest useful energy among the three absorbers with the highest thermal efficiency $\left(\eta_{\text {th }}=77.05 \%\right)$. The cylindrical shape receiver had the best flux distribution. Pavlovic et al. [3] determined thermal and optical efficiency of solar parabolic dish $34 \%$ and $35 \%$, respectively, using stainless steel corrugated spiral conical coil absorber located inside aluminum housing, and they also compared the three different heat transfer working fluids. The geometric properties of the thermal absorber decide the optimum thermal performance of the SPDC system. Bellos et al. [4] compared the conical spiral and flat spiral design of solar thermal absorber. Due to the shape of the conical absorber and the minimum number of convolutions resulting in conical absorber, it has the minimum effective area. This describes the heat losses due to shape are minimum. Thus, the performance and efficiency of the conical design were the best $[2,5,6]$. Spiraled tube conical cavity receiver welded on a hollow copper cylinder was developed using a storage carrier, i.e., molten salt. A thermocouple was used with a cylindrical component to obtain the temperature at a particular point in time. Thermal performance in the range of $58 \%$ to $77 \%$ was obtained for optimum flow characteristics [7]. A lightweight and low-cost solar dish collector was innovated to optimize the volumetric flow rate and working fluid outlet temperature using a spiral coil absorber to achieve optimum exergetic and thermal performances of the design. The idea behind the spiral absorber geometry was to get evenly distributed heat flux which improves the heat transfer rates in the absorber [8]. This concept was proved numerically by keeping the volume of the receiver constant with changing aspect ratio $[9,10]$. A modified U-shaped spiral air channel inside the solar thermal receiver was developed to minimize the convective heat losses up to $58 \%$ [11]. The conical absorber design has a very high performance which leads to higher absorbed solar energy [2, 3, 5-7]. Tian et al. [12] investigated the temperature range for seven working fluids to achieve the best and efficient performance level as mentioned in Table 1.

Order of thermal and exergetic efficiencies is as $\eta_{\text {th/exe }}=$ $\eta_{\mathrm{H}}>\eta_{\mathrm{Cu}}>\eta_{\mathrm{Cy}}$ (where $\eta_{\mathrm{H}}, \eta_{\mathrm{Cu}}$, and $\eta_{\mathrm{Cy}}$ are efficiencies for hemispherical, cubical, and cylindrical cavities, respectively) for inlet temperature of working fluid. The efficiency of cubical and cylindrical receivers was compared using low viscous oil working fluid, and thermal efficiencies were $65.14 \%$ and $56.44 \%$, respectively [13]. Dry working fluids have the worst performance over wet working fluids. Water is the most suitable heat transfer working fluid at low temperatures, and at higher temperatures, therminolis the best [12-16]. Zou et al. [17] determined an enhancement in thermal and hydraulic performance using a tubular flat spiral ribbed receiver for PTC. Materials that have higher absorption and lower reflections are used in solar still construction to increase distilled water produced by the system [18]. Ali et al. [19] suggested the honeycomb receiver of alumina by using a reasonable surface layer of the thermal receiver material as the absorption of the material affects the optical and thermodynamic character of the absorber. Li et al. [20]
TABLE 1: Temperature range for working fluids [10].

\begin{tabular}{lc}
\hline Working fluid & Temperature level \\
\hline Water and Therminol VP-1 & Up to $550 \mathrm{~K}$ \\
Molten salt & Up to $870 \mathrm{~K}$ \\
Liquid sodium & Up to $1100 \mathrm{~K}$ \\
Air, $\mathrm{CO}_{2}$, and $\mathrm{He}$ & Greater than $1100 \mathrm{~K}$ \\
\hline
\end{tabular}

investigated a collector of low concentrating solar thermal power by comparing the thermal efficiencies of darkening chrome-layered copper tubular absorber and multiwalled carbon nanotube receiver. Auti et al. [21] suggested stainless steel 312 for absorber material as its properties of fair corrosion resistance and of withstanding high temperatures. Although aluminum has the highest corrosion resistance, it is difficult for aluminum to bear high temperature. Satpute et al. [22] found an increment in HTC between HTWF and absorber at an increase in mass flow rate using an aluminum triangular absorber of aluminum in CPC. Impinging the receiver behaves more sensitive for high absorptive surface material. Total optical efficiency for cavity surface cylindrical receiver increases with increasing material absorptivity [23]. Wang et al. [24] examined four-receiver radius, $R=23 \mathrm{~mm}, 25 \mathrm{~mm}, 27.5 \mathrm{~mm}$, and $30 \mathrm{~mm}$. The smallest $23 \mathrm{~mm}$ receiver radius was chosen for a porous media receiver. However, little spillage occurred with this size of the receiver.

Pavlovic et al. [25] found the perfect location of the receiver was $2.1 \mathrm{~m}$ from the concentrator surface smaller than focal distance, $2.26 \mathrm{~m}$, to optimize the optical performance and to devise evenly distributed heat flux for the receiver. Figaj et al. [26] analyzed a hybrid system of solar chiller for the cooling unit by using an aluminum heat receiver. Zou et al. [27] investigated a novel design of a cylindrical hollow chamber receiver. The effect of hollow chamber length and the effective area of aperture based on the number of loops were studied for obtaining maximum efficiency.

In line with the literature, most of the researchers have been worked on absorbers' different geometries, absorbers' materials, and working fluid flowing inside the absorber, intending to optimize the performance by improving the SPDC system's efficiency. Considering all the literature review, it is the first time to design such an innovative absorber using the "convolution strategy." To design and analyze the thermal absorber in this way is to introduce an absorber having 5 convolutions of the copper tube by performing simulation for 3 convolutions and then 4 convolutions. This innovative design of the absorber consists of a novel feature of a $5 \mathrm{~mm}$ extension to the spiral tube at the exit and entry; hence, the turbulence effect could be overcome. Contact surface area of receiver/unit volume of HTWF is more for a tubular flat spiral receiver when compared to the conventional short cylinder receiver, which acts as a mechanism to enhance heat transfer. No gap in consecutive turns of coil and even distribution of heat flux on flat spiral coil tubular absorber reduce heat losses [28]. 


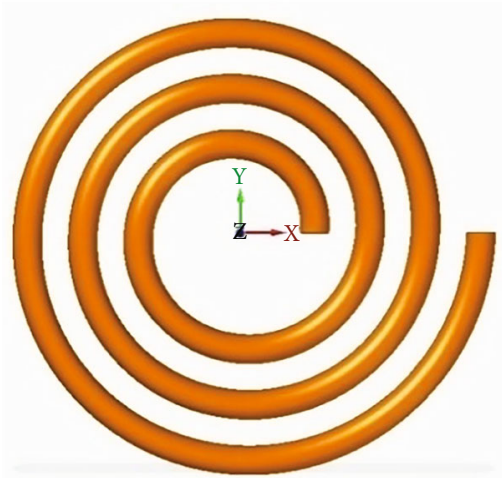

(a)

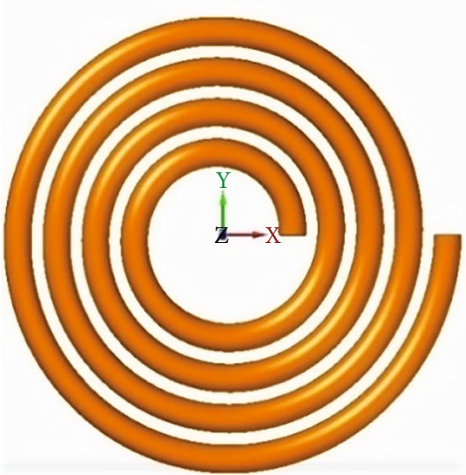

(b)

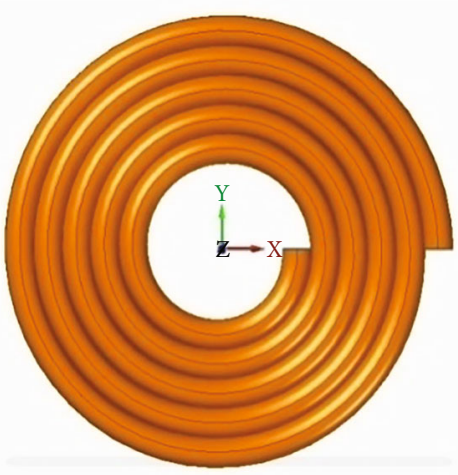

(c)

FIgURE 1: Spiral coil tubular copper absorber modeled on Solid Edge ST9 software as (a) 3 convolutions, (b) 4 convolutions, and (c) 5 convolutions.

It optimizes the thermal performance of the SPDC system [29]. Solid Edge ST9 software is used for constructing the optimized absorbers' geometry. The velocity of working fluid inside the absorber, steady-state thermal analysis, and pressure drop behavior are analyzed with the help of ANSYS 16.1 software. Dynamic behavior of the working fluid is analyzed with the object of using the kinetic energy of the working fluid in the operating mechanisms of various applications. Extension of the copper tube at entry and exit level minimizes the turbulence effect to prevent damages to the mechanism. Tube surface and working fluid temperature, working fluid velocity, pressure drop, heat flux distribution, and directional heat flux distribution for different convolutions are analyzed to design this absorber. After designing the absorber numerically, the construction of the copper tube spiral absorber is done. Testing results are used to validate the simulating results. Finally, a light weight and compact coiled tubular receiver in flat spiral form for a parabolic dish concentrator of $1.4 \mathrm{~m}$ is developed and tested.

\section{Thermal Performance Indicators}

Parametric definitions and energy balance equations used for developing an optimized thermal absorber are discussed in this section.

2.1. Concentration Ratio and Shape of Receiver. It is basically defined as the amount of solar radiant rays accumulated by a particular concentrator. There are 2 differently defined concentration ratios in use as follows:

(1) Optical Solar Concentration Ratio $\left(\mathrm{CR}_{\text {opts }}\right)$. It is the ratio of the incoming beam radiant energy on the effective reflective surface area $\left(I_{\text {sur }}\right)$ to radiant energy that reaches the receiver/absorber $\left(I_{\text {rec }}\right)[2,30]$ :

$$
\mathrm{CR}_{\text {opts }}=\frac{I_{\text {sur }}}{I_{\text {rec }}}
$$

(2) Geometric Concentration Ratio (CR). The ratio between the effective concentrator aperture $\left(A_{\mathrm{a}}\right)$ area and the effective receiver/absorber area $\left(A_{\text {rec }}\right)$ $[2,5,30-33]$ :

$$
\mathrm{CR}=\frac{A_{\mathrm{a}}}{A_{\text {rec }}}
$$

Calculations of the thermal efficiency related to the thermal absorber are done by using this geometric concentration ratio.

Shape of spiral coil tubular receiver is based on the following equation (3), as [34]

$$
R=R_{0} e^{a \theta} .
$$

2.2. Performance Calculations for the SPDC System. The efficiency of the SPDC system is determined by dividing the useful heat energy generated $\left(Q_{\mathrm{u}}\right)$ to the accessible solar irradiation heat energy on effective PD aperture surface $\left(Q_{s}\right)$, as $[3-5,30,35-37]$

$$
\eta_{\mathrm{th}}=\frac{Q_{\mathrm{u}}}{Q_{\mathrm{s}}}
$$

Balancing equation in the HTWF volume is given as $[3-5,28,35,37-40]$

$$
Q_{\mathrm{u}}=m \cdot C_{\mathrm{p}} \cdot\left(T f_{(\text {out })}-\mathrm{T}_{\mathrm{f}(\mathrm{in})}\right),
$$

where

$$
m=\frac{\rho \cdot v}{3600}(\mathrm{~kg} / \mathrm{s})
$$

where $\rho$ is in $\mathrm{kg} / \mathrm{L}, v$ is in $\mathrm{L} / \mathrm{h}$, and 3600 is in $\mathrm{s} / \mathrm{h}$.

And the available solar irradiation heat energy on effective PD aperture surface is determined as $[3-5,35]$

$$
Q_{\mathrm{s}}=A_{\mathrm{a}} \cdot G_{\mathrm{b}} .
$$




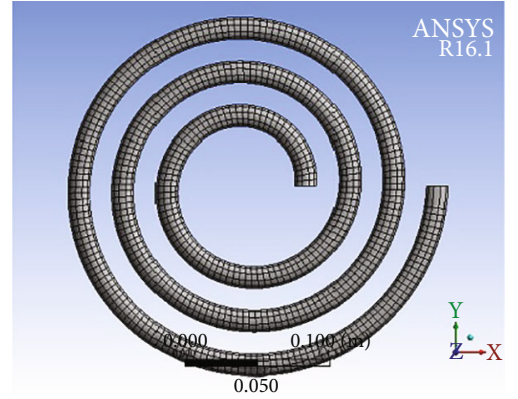

(a)

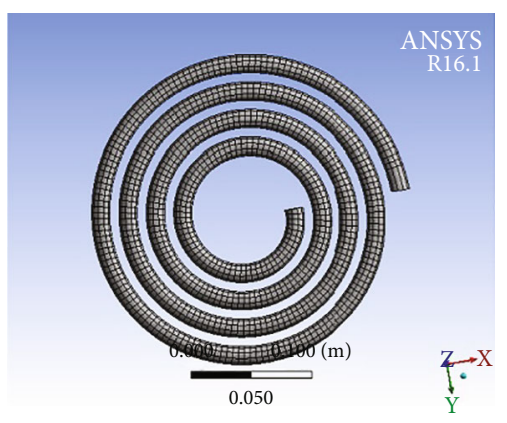

(b)

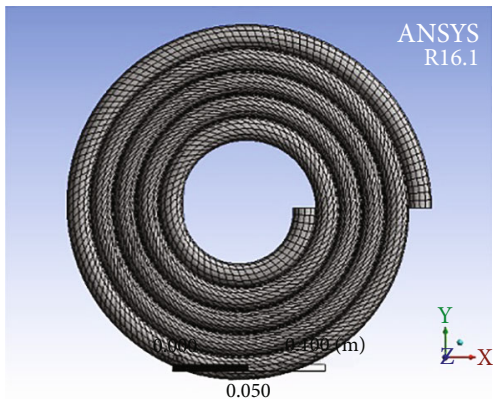

(c)

FIGURE 2: Spiral coil tubular copper absorber mesh on ANSYS 16.1 software as (a) 3 convolutions, (b) 4 convolutions, and (c) 5 convolutions.

Table 2: Description of mesh data.

\begin{tabular}{lccc}
\hline Number of convolutions of coil & No. of elements & No. of nodes & ANSYS modules \\
\hline 3 convolutions & $34704 \& 6678$ & $42716 \& 33034$ & \\
4 convolutions & $42372 \& 8010$ & $52056 \& 39670$ & ANSYS CFX and steady-state thermal analysis \\
5 convolutions & $41080 \& 11592$ & $52428 \& 56530$ & \\
\hline
\end{tabular}

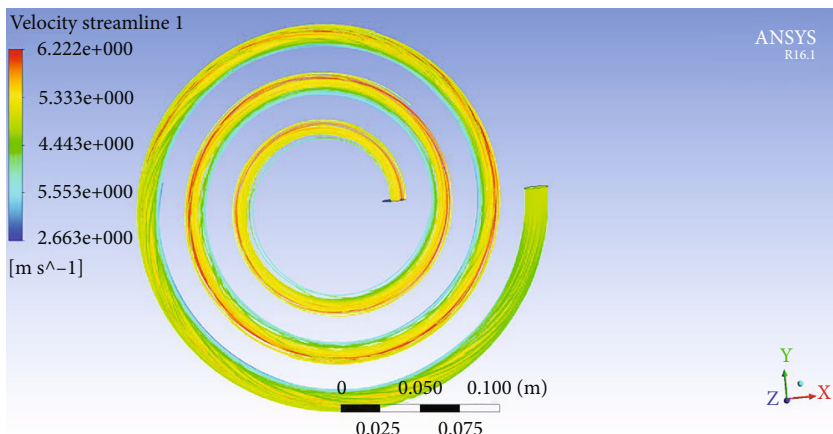

(a)

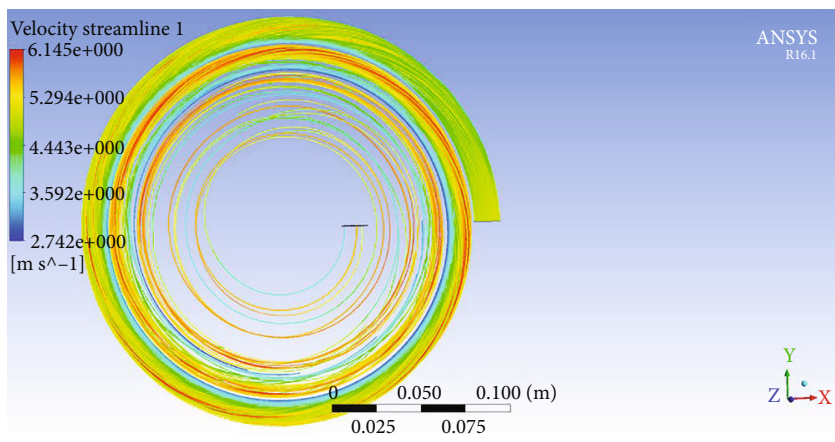

(c)

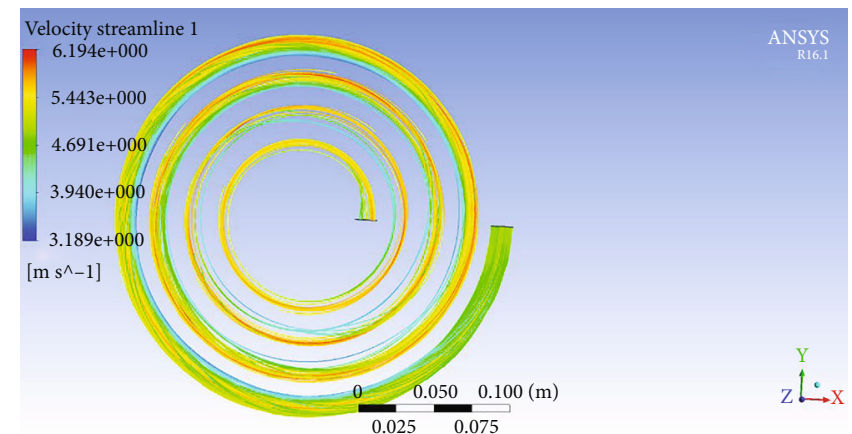

(b)

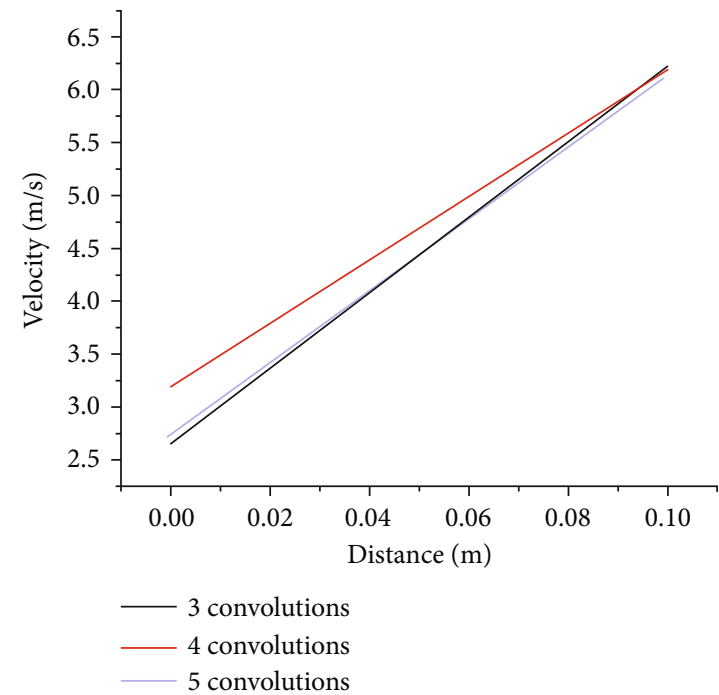

(d)

Figure 3: Streamlines of flow through coil of (a) three convolutions, (b) four convolutions, (c) five convolutions, and (d) velocities of streamlines at different positions of coil with varying number of convolutions. 


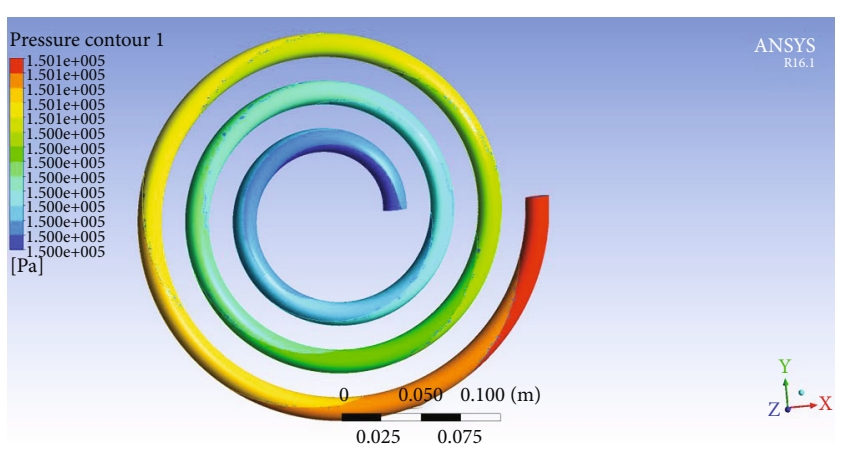

(a)

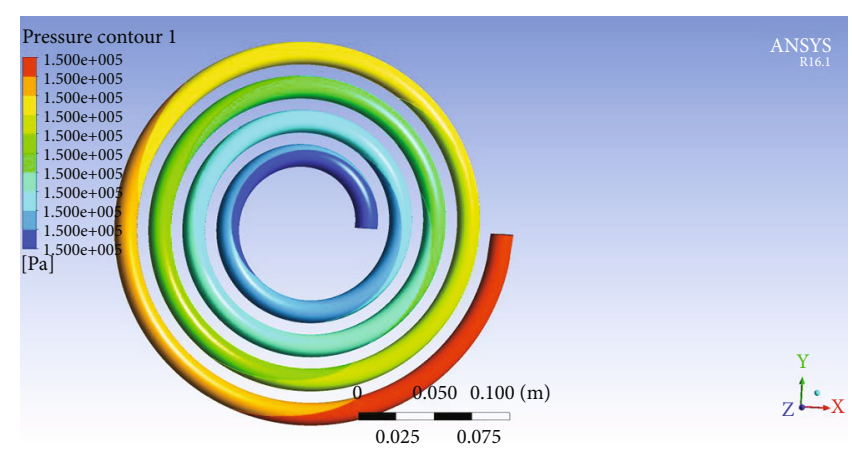

(b)

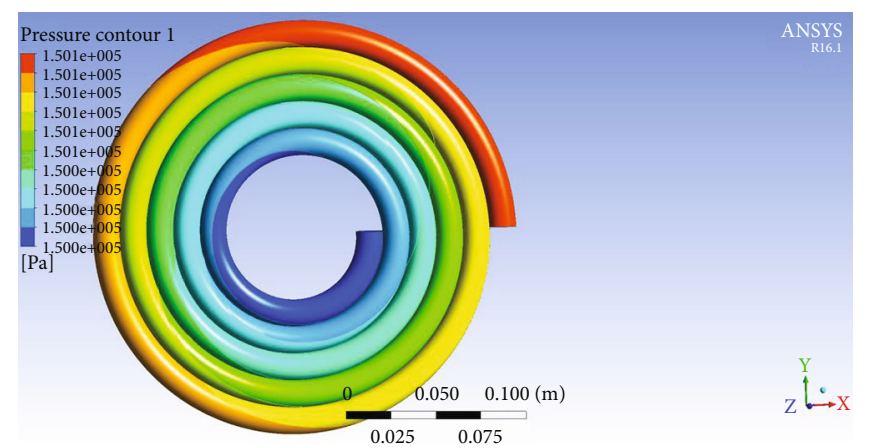

(c)

FIgURE 4: Pressure contours for coil of (a) three convolutions, (b) four convolutions, and (c) five convolutions.

However, some of the radiations do not concentrate on the absorber due to design constraints. These account for the radiation losses.

2.3. Energy Balance Equations for Spiral Coil Tubular Absorber. The absorbed solar energy $\left(Q_{a b s}\right)$ is given as $[3,5,41,42]$

$$
Q_{\mathrm{abs}}=Q_{\mathrm{u}}+Q_{\mathrm{loss}},
$$

where [36]

$$
Q_{\text {loss }}=Q_{\text {rad }}+Q_{\text {conv,in }}+Q_{\text {conv,ex }}
$$

Also, the absorbed energy may be defined as $[2-5,28,30,40]$

$$
Q_{\mathrm{abs}}=\eta_{\mathrm{opts}} \cdot Q_{\mathrm{s}},
$$

where

$$
\eta_{\text {opts }}=\text { Reflectance } \cdot \text { Absorbance } \cdot \text { Intercept Factor. }
$$

Intercept factor (" $\gamma$ ") is calculated by determining the actual amount of energy concentrated on the absorber and the radiation losses caused by design constraints of PD as [3]

$$
\gamma=\frac{\text { Energy intercepted by the spiral coil tubular receiver }}{\text { Energy reflected by the parabolic dish collecter }} \text {. }
$$

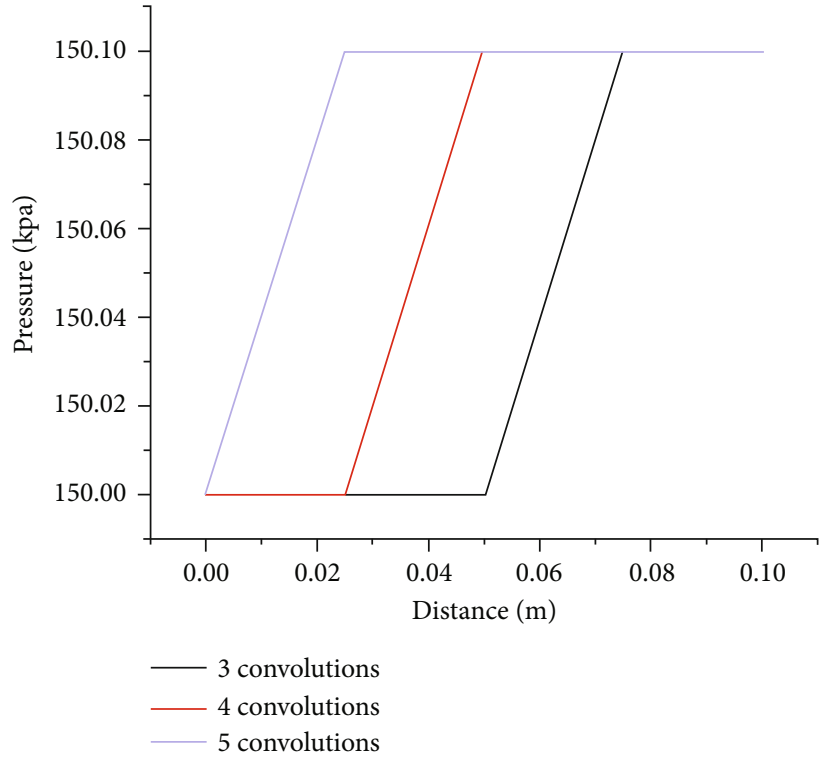

FIGURE 5: Pressure at different positions of coil with varying number of convolutions.

2.4. Heat Transfer Equations for Spiral Coil Tubular Absorber. The energy transfer from the receiver to the HTWF is given as $[3,4]$

$$
Q_{\mathrm{u}}=A_{\text {rec }} \cdot h_{\mathrm{f}} \cdot\left(T_{\text {rec }}-T_{\text {fm }}\right),
$$




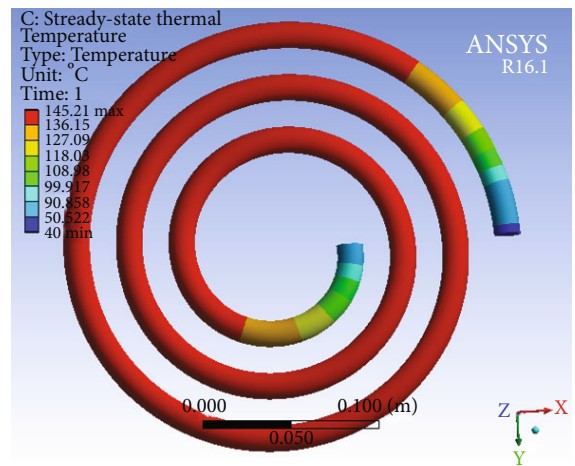

(a)

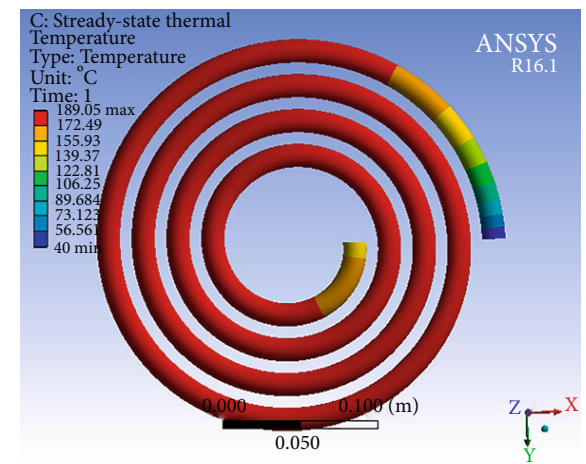

(b)

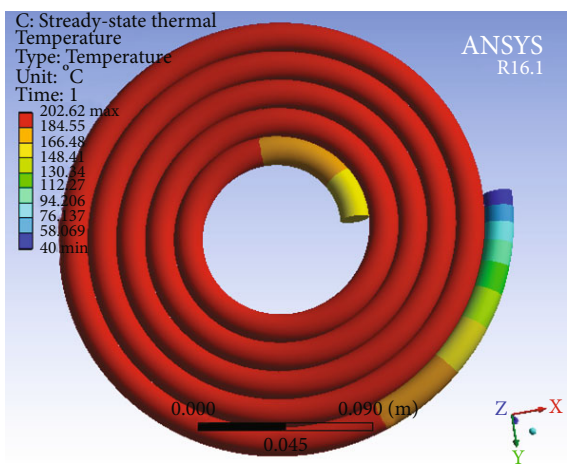

(c)

Figure 6: Temperature distribution through (a) three convolutions of coil, (b) four convolutions of coil, and (c) five convolutions of coil.

where

$$
h_{\mathrm{f}}=\left(\frac{d_{\mathrm{rec}}}{k_{\mathrm{f}}}\right) \cdot \frac{\left(f_{r} / 8\right) \cdot R_{e} \cdot P_{r}}{1+12.8 \cdot \sqrt{f_{r} / 8 \cdot\left(P_{r}^{0.68}-1\right)}} .
$$

2.5. Characteristics of Fluid Flow inside the Spiral Coil Tubular Receiver. On account of curvature of the coil centrifugal force is found. With this force, secondary flow is set up owing to the curvature nature of the spiral coil tube. This secondary flow has the characteristic of escalating the mixing of fluid particles rapidly. Swirling motion within the fluid due to mixing activity enhances the heat and mass transfer as well as fluid transfer across cross section. This concept is used to shift HTF from inlet boundary to outlet boundary with mean flow velocity $\left(v_{\theta_{i}}\right)$ at cross section. $M_{x}$ is the shifting parameter defined by equation (15), as [34]

$$
M_{x}=\sum_{i=0}^{n}\left\{\frac{1}{r_{i}} \cdot\left(\frac{\Delta A_{i} v_{\theta_{i}} x_{i}}{\Delta A_{i} v_{\theta_{i}}}\right)\right\} \text {. }
$$

The friction factor $f$ is used to determine the consequence of pressure drop in the spiral coil tubular absorber $[3-5,34]$

$$
f=\frac{-(\Delta P / L) d_{h}}{(1 / 2) \rho v_{\theta}^{2}}
$$

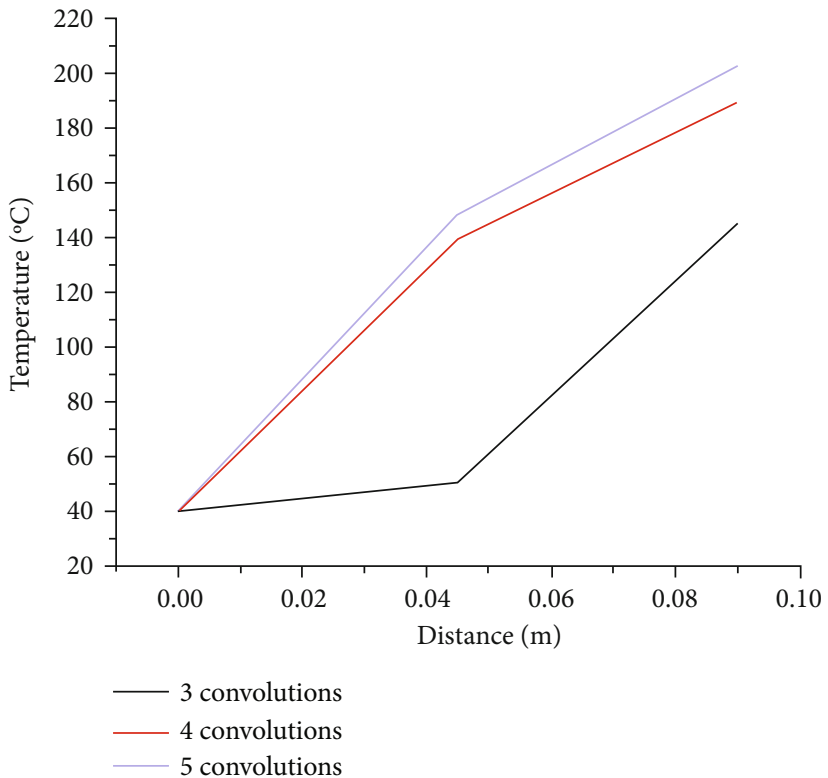

FIgURE 7: Temperature values at different positions of coil with varying number of convolutions.

Modified critical Reynolds' number for turbulence flow can be calculated by equation (17), as $[4,34]$

$$
R_{e, \mathrm{cr}}=2300\left[1+8.6\left(\frac{d_{i}}{2 R}\right)^{0.45}\right] \text {. }
$$




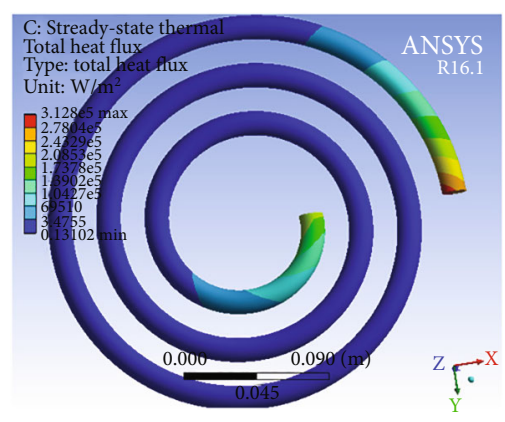

(a)

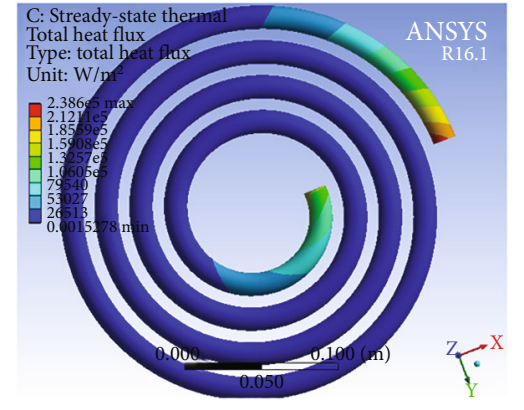

(b)

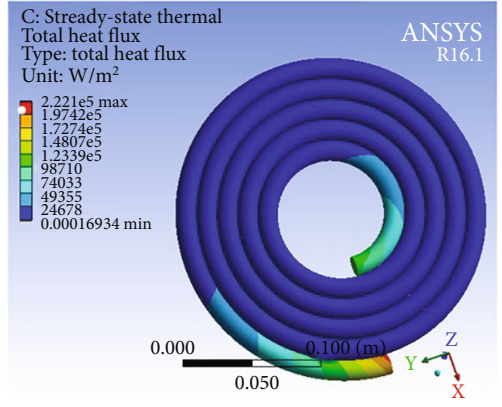

(c)

Figure 8: Heat flux distribution through (a) three convolutions, (b) four convolutions, and (c) five convolutions of coil.

Range of $R_{e}$ depends on the mode of the application and type of fluid flow. The main equations are described as follows [34, 43]:

General continuity equation

$$
\frac{\partial}{\partial x_{i}}\left(\rho u_{i}\right)+\frac{\partial}{\partial y_{j}}\left(\rho v_{j}\right)+\frac{\partial}{\partial z_{k}}\left(\rho w_{k}\right)+\frac{\partial}{\partial t}(\rho)=0
$$

Momentum equation

$$
\frac{\partial}{\partial x_{i}}\left(\rho u_{i} u_{j}\right)=-\frac{\partial p}{\partial x_{i}}+\frac{\partial}{\partial x_{i}}\left[\mu\left(\frac{\partial u_{i}}{\partial x_{j}}+\frac{\partial u_{j}}{\partial x_{i}}\right)\right]
$$

The three applied boundary constraints for this flow field are described as follows:

(i) Flow rate of mass at entry is kept constant

(ii) The exit condition is the second type (Neumann)

(iii) At the peripheral walls, there are no slip conditions

\section{Numerical Simulation of Spiral Coil Tubular Absorber}

Graphical contours and plots are obtained for velocity, pressure, temperature, heat flux, and directional heat flux by ANSYS CFX, ANSYS Fluent, and steady-state thermal analysis. Model is developed in Solid Edge ST9 software. After transporting the model geometry in ANSYS 16.1, meshing is performed. The final solution is obtained by defining the boundary. In the entry of water, the flow mass rate and the uniform temperature were selected. After this, the static pressure in the outlet of the tube was set to be environmental. The last boundary condition is the heat convection between the coil outer surface and the environment. It is important to say that for determining a different operating condition, the water inlet temperature was changed in the proper boundary condition. After this step, the radiation surfaces were selected. The reflector was set to be a symmetrical surface in order to reflect the sun rays.

A copper absorber of spiral coil shape is to be modeled on Solid Edge ST9 software. For efficient and optimal perfor-

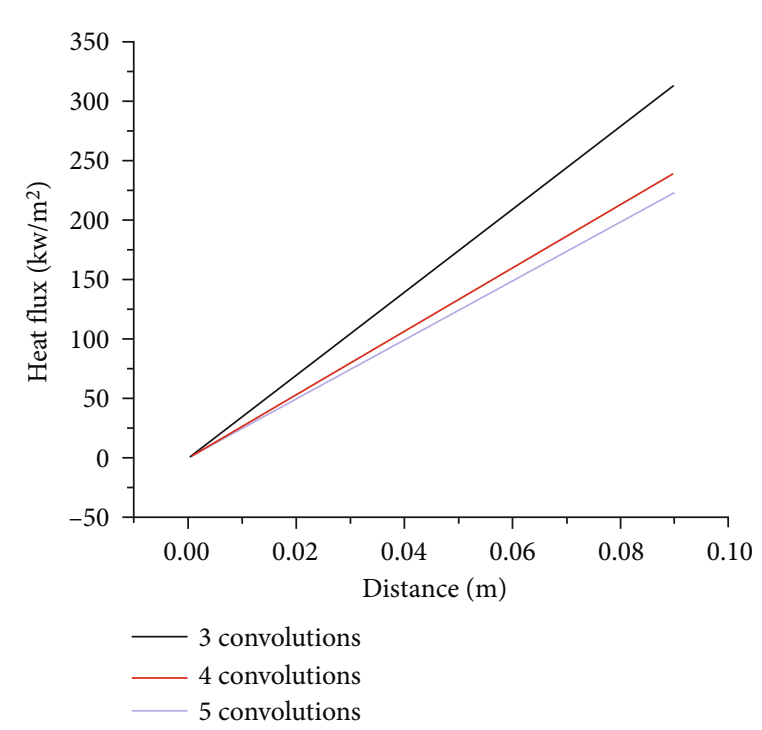

Figure 9: Heat flux at different positions of coil with varying number of convolutions.

mance, three coil models are modeled for 3,4 , and 5 convolutions, respectively. These are depicted in Figure 1.

The length of the coil tube is variable, and the inner and outer diameters of these coils are kept constant. The gap of the coils, as shown in Figures 1(a) and 1(b) is responsible for energy (heat) loss, and Figure 1(c) is depicted for no loss of energy (heat) due to gap because in this coil, there is no gap between the convolutions.

After creating a geometric model, the geometry of the model has been divided into small elements for flow analysis; this process of making small elements is called meshing, as shown in Figure 2. This step is followed by geometry construction for performing detailed and microscopic analysis for more detail. The process involves breaking up the geometry into nodes and elements for a detailed analysis of the entire geometry. For part meshing, different mesh size has been given to different individual parts.

Mesh data for different parts and their different conditions has been given in Table 2 .

3.1. Velocity Distribution for Absorber. Obtained contour for spiral coil absorber for three, four, and five convolutions are 


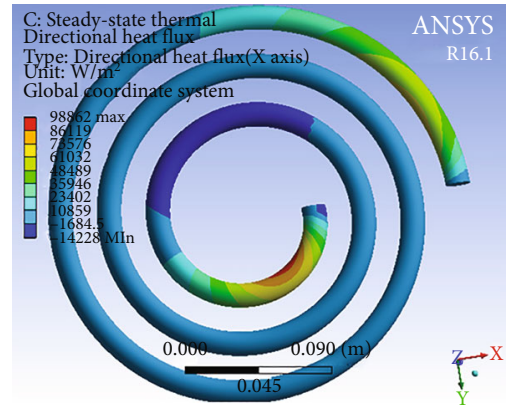

(a)

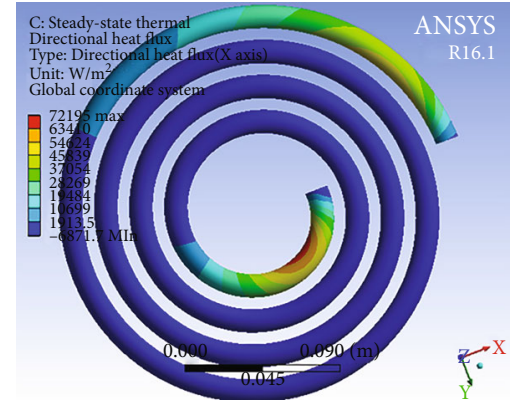

(b)

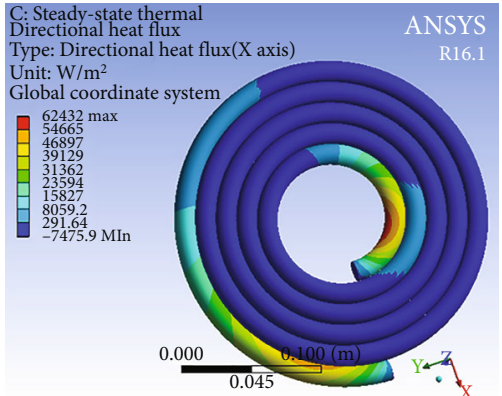

(c)

Figure 10: Directional heat flux distribution for (a) three convolutions, (b) four convolutions, and (c) five convolutions of coil.

depicted in Figure 3. The fewer convolution coils have more gaps, and more convolution coils have less gaps. After performing a practical approach, five convolution coil gives the best result among all. The flow of working fluid is streamlined and smooth. From these contours, it is clear that the velocities of streamlines at the outlet of coil increases with an increasing number of convolutions which in turn will operate efficiently the CSP-based irrigation water pump and/or other mechanisms/devices. But, due to consideration of the variable (increasing) length of the tube, velocity decreases as an increasing number of convolutions. Hence, finally, it gives nearly equal velocity at outlet in all three cases of absorber coil as depicted in Figure 3(d).

There is turbulence at outlet in actual working condition, which can damage the mechanism/system due to the sudden impact of pressurized steam; therefore, a $5 \mathrm{~mm}$ extension is given both at inlet and outlet of the coil.

3.2. Pressure Distribution for Absorber. Outlet pressure of coil should be matched with the inlet condition of the inlet steam chamber of the system, which is found in the simulation is $150 \mathrm{kPa}$ in the condition of $100 \%$ inlet opening as depicted in Figure 4.

Suppose steam pressure changes its values inside the tube. In that case, there may be possibilities of impacts, and due to these impacts and jerks, the coil tube may deform, which in turn is responsible for increasing the pump's cost because copper coil may deform quickly. To overcome this drawback, steam pressure inside the coil tube must be constant through the journey of working fluid inside it.

It is clear that the pressure at different positions of coil with varying number of convolutions is almost constant throughout the coil as shown in Figure 5.

3.3. Temperature Distribution for Absorber. As the heat loss decreases, temperature increases on an increasing number of convolutions of absorber coil because the gap decreases as depicted in Figures 6(a)-6(c). The coil shape is spiral, resulting in even distribution of the temperature and heat, and getting that desire results in simulation of the absorber coil. The chances of heat loss are very much reduced compared to other shapes of the absorber. The five convolution coil is closely packed, and it has no space between nearby convolutions.

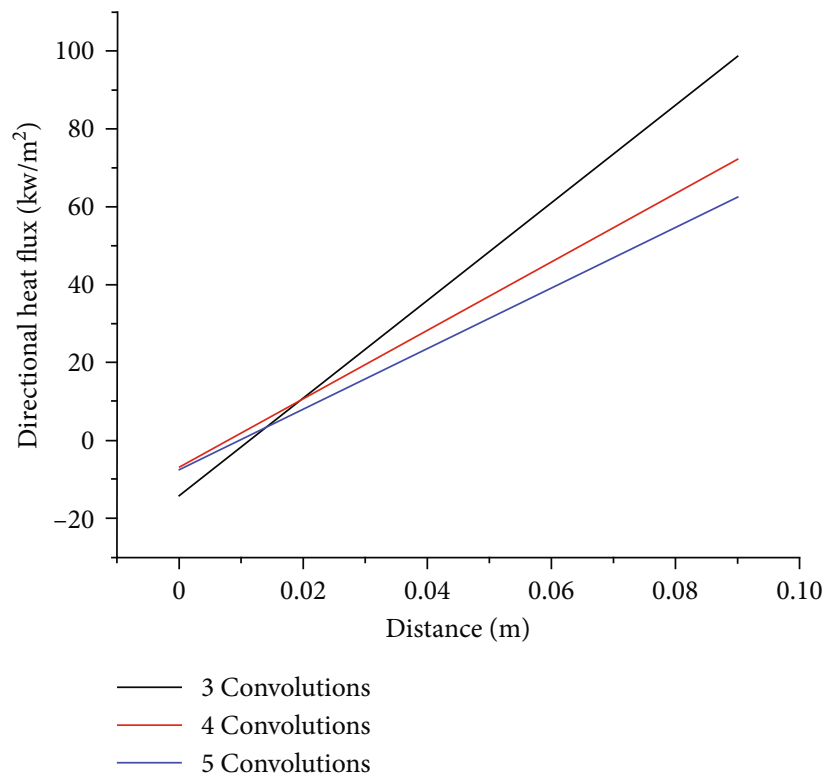

FIgURE 11: Directional heat flux at different positions of coil with varying number of convolutions.

It is clear that temperature values at the outlet of the coil increase with an increasing number of turns and will be sufficient to convert water into steam of very high temperature as shown in Figure 7.

3.4. Heat Flux Distribution. As the heat absorbing area increases, the heat flux decreases, and the following results of simulation for heat flux distribution are also favoured the same as shown in Figures 8(a)-8(c).

Simulated contours of heat flux are depicted in Figure 9; heat flux at the coil outlet decreases with an increasing number of the coil.

3.5. Directional Heat Flux Distribution. As the heat absorbing area increases, the directional heat flux decreases, and the following results of simulation for directional heat flux distribution are also favoured the same as shown in Figures 10(a)-10(c).

Simulated contours of directional heat flux are depicted in Figure 11; directional heat flux at the coil outlet decreases with an increasing number of convolutions of coil. 


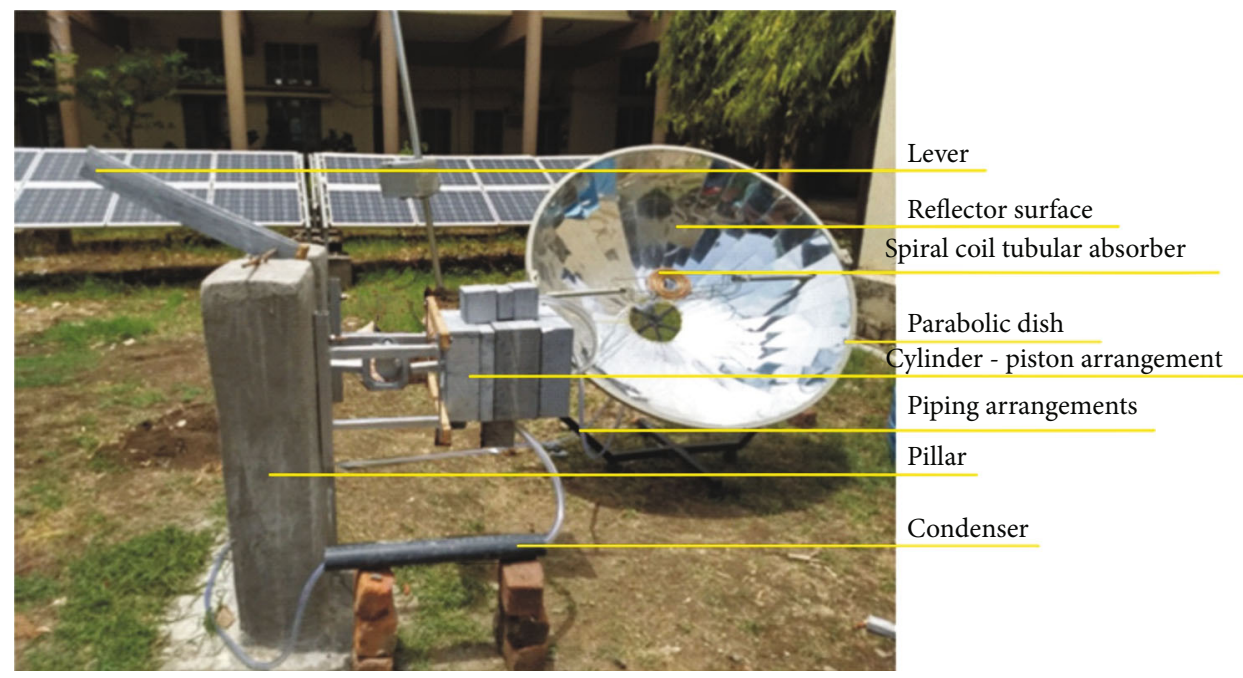

FIGURE 12: Modified solar thermal absorber installed in SPDC for solar water thermal pump system.

\section{Experimental Setup and Instrumentation}

4.1. Experimental Setup. The experimental setup has been installed on the lawn of the Energy Centre of Maulana Azad National Institute of Technology, Bhopal (India). According to NREL, Bhopal has 23.250 latitudes and 77.450 longitudes. Annual average direct normal irradiance is $5.61 \mathrm{kWh} / \mathrm{m}^{2} /$ day which is maximum in April and May, $7.27 \mathrm{kWh} / \mathrm{m}^{2} /$ day and $7.51 \mathrm{kWh} / \mathrm{m}^{2} /$ day, respectively.

The modified spiral coil tubular absorber is set on the focus point of the SPDC, as shown in Figure 12. This combination of $\mathrm{PD}$ and absorber may be used in various applications. Here, it is used for driving an irrigation water pump system using its kinetic energy and may also be used for heating and drying purposes. Pumped water enters into the absorber and takes heat through a copper tube.

The spiral coil tubular absorber is shown in Figure 13. Copper is used for making this spiral coil tubular absorber. The thermal conductivity of copper is $385 \mathrm{~W} / \mathrm{mK}$. Therefore, it is an excellent absorber of heat and may be used for heating and drying applications. Here, this absorber coil is used as a device to convert pressurized and pumped working fluid from the liquid stage to the vapor stage (steam). The coil has 5 convolutions and a $5 \mathrm{~mm}$ extension at entry and exit. The specifications of the spiral coil tubular absorber and its material properties are given in Table 3. The innovation of this system is the spiral absorber geometry which is an alternative way to create a low-cost system. This configuration is simple, and it helps to create a reactively uniform heat flux distribution.

The readings of measured and experimental parameters were taken on $21^{\text {st }}$ January, $17^{\text {th }}$ February, $23^{\text {rd }}$ March, $25^{\text {th }}$ April, and $12^{\text {th }}$ May in the year 2020 for the duration from 8:30 A.M. to 6:30 P.M. for every hour. Then, mean was calculated for whole day readings of a particular month, and this mean value was considered for that month.

A schematic diagram of the experimental setup developed for performance tests is presented in Figure 14. The working principle of this pumping system can be explained

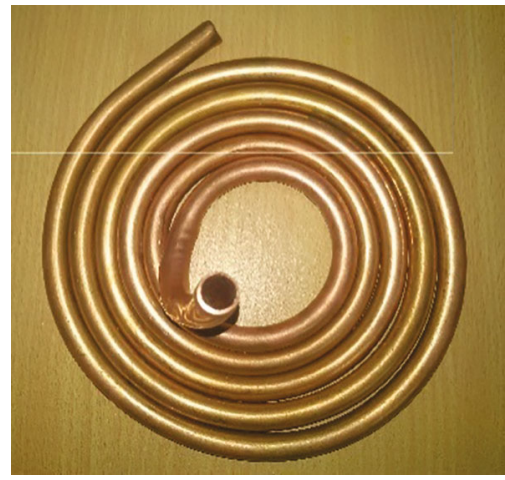

Figure 13: Modified spiral coil tubular thermal absorber.

TABle 3: Design parameters, material properties, and dimensions of collector and modified absorber.

\begin{tabular}{lc}
\hline Description & Value (all dimensions in mm) \\
\hline Diameter of PD & 1400.0 \\
Focal length of the PD & 272.2 \\
Depth of the PD & 450.0 \\
Rim angle & $45^{\circ}$ \\
Material of PD & Anodized aluminium \\
Collector reflectivity & 0.82 \\
Intercept factor & 0.98 \\
Length of spiral tube & 2286.0 \\
Diameter of spiral tube & 10.0 \\
Inner diameter of copper coil & 76.2 \\
Outer diameter of copper coil & 152.4 \\
Emittance value for absorber & 0.11 \\
Absorbance value for absorber & 0.836 \\
Tube material & Copper \\
Thermal conductivity of copper & $385 \mathrm{~W} / \mathrm{mK}$ \\
\hline
\end{tabular}




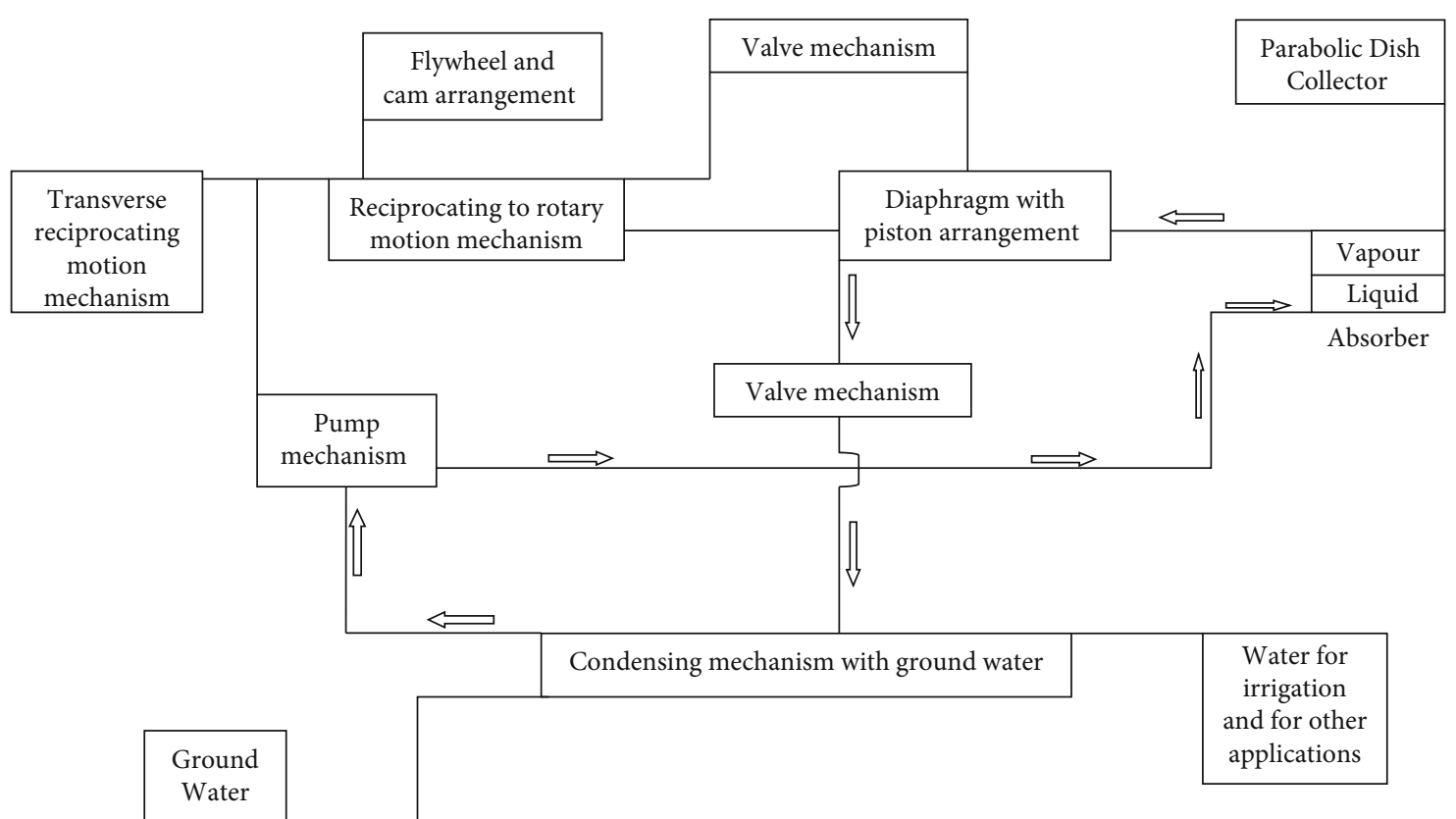

FIgURE 14: HTWF circulation layout along with water pumping mechanism.

TABLE 4: Output obtained from SPDC system using modified absorber.

\begin{tabular}{|c|c|c|c|c|c|c|c|c|c|c|c|c|c|}
\hline \multirow[b]{2}{*}{ Month } & \multirow[b]{2}{*}{$\begin{array}{l}T_{\mathrm{f}(\mathrm{in})} \\
\left({ }^{\circ} \mathrm{C}\right)\end{array}$} & \multicolumn{3}{|c|}{ Measured parameters } & \multicolumn{3}{|c|}{ Experimental } & \multicolumn{3}{|c|}{ Numerical } & \multicolumn{3}{|c|}{ Deviation } \\
\hline & & $\begin{array}{l}V_{\mathrm{f}(\text { out })} \\
(\mathrm{m} / \mathrm{s})\end{array}$ & $\begin{array}{c}v \\
(\mathrm{~L} / \mathrm{h})\end{array}$ & $\begin{array}{c}\mathrm{G}_{\mathrm{b}} \\
\left(\mathrm{kWh} / \mathrm{m}^{2} / \text { day }\right)\end{array}$ & $\begin{array}{c}T_{\mathrm{abs}(\max )} \\
\left({ }^{\circ} \mathrm{C}\right)\end{array}$ & $\begin{array}{l}T_{\mathrm{f}(\text { out })} \\
\left({ }^{\circ} \mathrm{C}\right)\end{array}$ & $\begin{array}{l}\eta_{\text {th }} \\
(\%)\end{array}$ & $\begin{array}{c}T_{\mathrm{abs}(\max )} \\
\left({ }^{\circ} \mathrm{C}\right)\end{array}$ & $\begin{array}{l}T_{\mathrm{f}(\text { out })} \\
\left({ }^{\circ} \mathrm{C}\right)\end{array}$ & $\begin{array}{l}\eta_{\text {th }} \\
(\%)\end{array}$ & $T_{\mathrm{abs}(\max )}$ & $T_{\mathrm{f}(\text { out })}$ & $\begin{array}{c}\eta_{\text {th }} \\
(\%)\end{array}$ \\
\hline Jan & 30 & 6.145 & 6948 & 10.9 & 220 & 218.6 & 57.93 & 202.62 & 199.32 & 54.21 & 0.079 & 0.088 & 6.42 \\
\hline Feb & 34 & 6.8 & 7690 & 11.4 & 234 & 232.9 & 62.83 & 219.32 & 216.65 & 59.61 & 0.063 & 0.070 & 5.12 \\
\hline March & 40 & 7.2 & 8140 & 11.8 & 258 & 256.4 & 66.94 & 244.12 & 242.13 & 64.16 & 0.053 & 0.056 & 4.15 \\
\hline April & 42 & 7.3 & 8260 & 12.2 & 272 & 269.8 & 64.94 & 264.74 & 262.20 & 66.17 & 0.027 & 0.028 & 1.89 \\
\hline May & 44 & 8.1 & 9160 & 12.7 & 296 & 294.2 & 75.98 & 289.59 & 288.15 & 74.86 & 0.022 & 0.021 & 1.47 \\
\hline
\end{tabular}

clearly by considering a simple Rankine cycle. The working fluid is water which remains water for half cycle and converts into steam for the remaining half of the cycle [36]. Here, an arrangement of piston-cylinder and diaphragm is used to convert the steam enthalpy into the mechanical energy. In this work, the collector is taken as a parabolic solar dish concentrator along with a solar thermal spiral tubular coil absorber. The working fluid (water) is pressurized in pumping arrangement going through the collector and got heated up to around $150^{\circ} \mathrm{C}$ to $300^{\circ} \mathrm{C}$ depending on the available solar beam radiation at particular time interval. The flow of working fluid is also shown in the figure in which the Rankine cycle is shown with the help of arrows. Pressurized water enters first in the absorber coil. With the help of a solar concentrator, the sun rays are focused on the absorber coil and the temperature will increase. Range of temperature in absorber coil is $150^{\circ} \mathrm{C}$ $300^{\circ} \mathrm{C}$. Now, water is converted into steam. Pressurized steam enters first into the pressure chamber, where steam pressure is to be measured. From then, it enters to valveblock arrangement. These valves are attached to the cam arrangement with the help of this; the valves of inlet and outlet open and close at the particular timing. When the valve comes in open condition, steam enters to the piston-cylinder and diaphragm-chamber arrangement. Pressurized steam pushes the diaphragm and piston outwards and exits by the outlet valve into the condenser. The piston is pushed by the pressurized steam in outward direction. With the help of this mechanism and due to inertia effect, the piston again comes towards the cylinder head and makes a complete rotation. This moves the lever arrangement and then a belt and rope are there for lifting the underground water. When the lever upper arm revolves, this helps to reciprocate the pumping arrangement and this creates the pressure of the water (working fluid) which is flowing into absorber coil. Then, this working fluid exits from the piston-cylinder arrangement and enters into the condenser. The working fluid gets cooled and then enters to pumping arrangement and then to absorber coil which completes the working cycle. The solar energy first gives its heat to water, this water is converted into steam, then pressurized steam runs the mechanism, and with the help of mechanical energy of this mechanism, pump is operated [29]. 


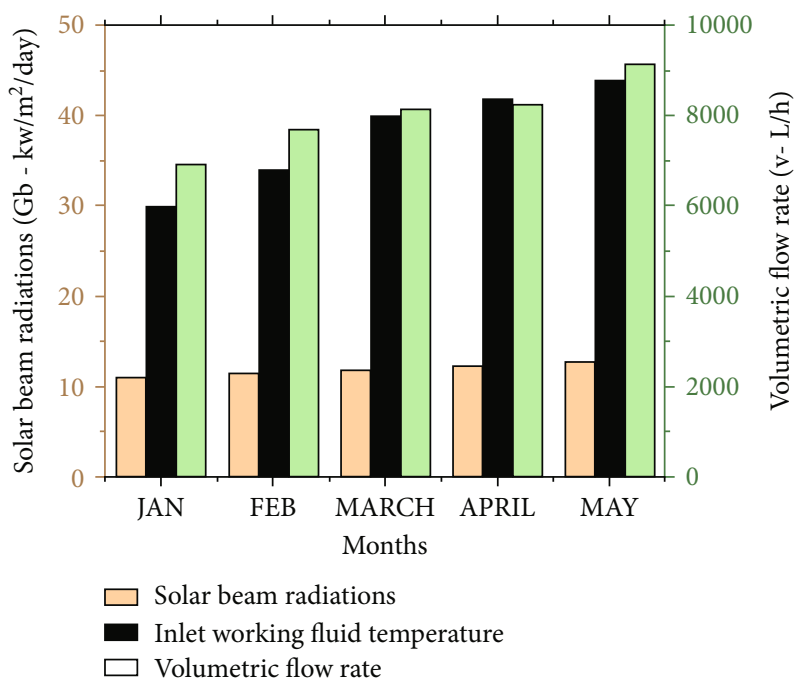

Figure 15: Measured data for solar beam radiations, inlet working fluid temperature, and volumetric flow rate from January 2020 to May 2020.

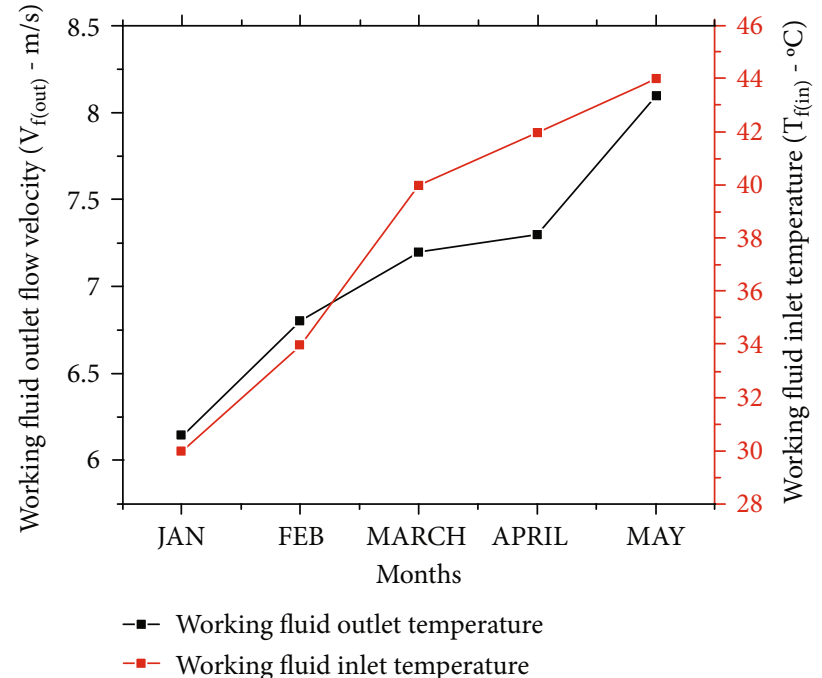

FIGURE 16: Behavior of working fluid outlet flow velocity and working fluid inlet temperature from January to May.

4.2. Measuring Instruments. The main measuring instruments used during the experiments are as follows:

(1) Flow meter: the volumetric water flow rate $(v)$ is measured with this flow meter of accuracy of $1 \%$

(2) Pt100 thermometers: water inlet temperature $\left(T_{\text {in }}\right)$, water outlet temperature $\left(T_{\text {out }}\right)$, and ambient temperature $\left(T_{\mathrm{m}}\right)$ are measured with this thermometer with an accuracy of $0.1 \mathrm{~K}$

(3) Pyranometers: the solar irradiation (global and diffuse) was measured with two pyranometers of $1 \%$ accuracy

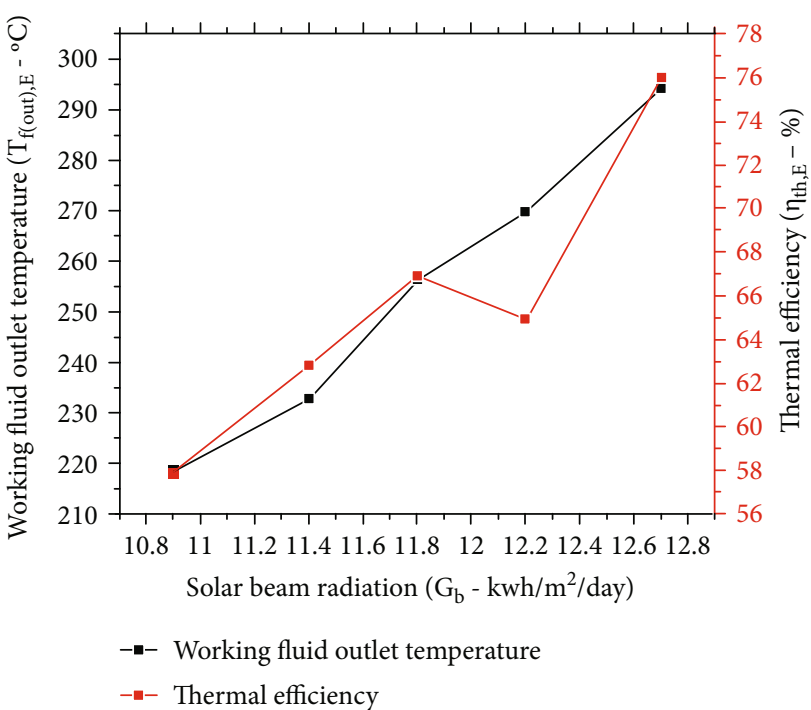

FIGURE 17: Behavior of working fluid outlet temperature and thermal efficiency with solar beam radiation.

\section{Results and Discussion}

Testing of modified spiral coil tubular absorber with solar thermal dish concentrator was performed from January 2020 to May 2020 at Energy Centre Lawn of Maulana Azad National Institute of Technology situated in the capital (i.e., Bhopal) of Madhya Pradesh state of India. The obtained output details, measured parameters, and deviation between experimental and numerical results are communicated in Table 4.

Figure 15 depicts the three measured parameters (solar beam radiations, inlet working fluid temperature, and volumetric flow rate) that increase continuously from January 
TABLE 5: Thermal properties of working fluid at outlet temperature when $p=150 \mathrm{kPa}$.

\begin{tabular}{lccccc}
\hline$T_{\mathrm{f}(\text { out })}\left({ }^{\circ} \mathrm{C}\right)$ & $\rho(\mathrm{kg} / \mathrm{L})$ & $m(\mathrm{~kg} / \mathrm{s})$ & $C_{\mathrm{p}}(\mathrm{kJ} / \mathrm{kg} \mathrm{K})$ & $k_{\mathrm{f}}(\mathrm{W} / \mathrm{mK})$ & $h_{\mathrm{ef}}(\mathrm{kJ} / \mathrm{kg})$ \\
\hline 218.6 & 0.0006653202 & 0.00133803 & 1.99379577 & 0.03522136135775 & 2910.2283315212 \\
232.9 & 0.0006460501 & 0.00138003 & 1.99551452 & 0.036601677039559 & 2938.7499503425 \\
256.4 & 0.0006167785 & 0.00139460 & 2.00132672 & 0.038944475744472 & 2985.7066147087 \\
269.8 & 0.0006012796 & 0.00137960 & 2.00588169 & 0.040318305585457 & 3012.5540644076 \\
294.2 & 0.0005750168 & 0.00146309 & 2.015843001 & 0.042884156799922 & 3061.615277978 \\
\hline
\end{tabular}

to May. Solar beam radiation is the main responsible factor for this enhancement as the sun rays enter into earth surface; these are captured by solar PD for concentrating onto a modified absorber. The solar beam radiations reached to PD surface in April, and May has the highest values. Thus, the inlet working fluid temperature and volumetric flow rate also attain maximum values for these months.

A rapid increase in working fluid outlet flow velocity and working fluid inlet temperature was recorded from January to May, as shown in Figure 16. Performance of modified absorber for working fluid outlet flow velocity increases as the solar beam radiation values increases. And this outlet flow velocity affects the volumetric flow rate, which is measured through flow meter. Using the values of volumetric flow rate, mass flow rate was obtained for each reading.

The highest value of working fluid outlet temperature was obtained for May. It increases with the value of solar beam radiation, as shown in Figure 16. The performance of modified absorber during the whole period was optimum, but a noticeable change in the month of April was seen. At this particular point in time, the experimentally obtained thermal efficiency of the system falls to $64.94 \%$ from $66.94 \%$ in March. Except for this point of time, thermal efficiency increases as the solar beam radiation value increases as depicted in Figure 17.

This happened due to the inherent property of water (HTWF). At the working fluid temperature at the exit of the modified absorber for this month, the density of water decreased drastically and affected the mass flow rate of HTWF. It happened in May, but the mass flow rate for this point of time increased in order, as shown in Table 5 and Figure 18.

Figure 18 depicts that the numerically obtained thermal efficiency increases with an increase in mass flow rate every time. But experimentally obtained thermal efficiency of the system decreases in April and again increases for May.

Thermal efficiency changes in three stages as depicted by Figures 19 and 20. In the case of numerically obtained thermal efficiency, the first and last stages show that the values of the efficiency increase rapidly and the midstage between $11.8 \mathrm{kWh} / \mathrm{m}^{2} /$ day and $12.2 \mathrm{kWh} / \mathrm{m}^{2} /$ day (solar beam radiation) or between $8140 \mathrm{~L} / \mathrm{h}$ and $8260 \mathrm{~L} / \mathrm{h}$ (volumetric flow rate) thermal efficiency enhancement came slowly.

Experimentally obtained values of thermal efficiency increase rapidly in the first and the last stage. However, in the mid-mid-stage, between $11.8 \mathrm{kWh} / \mathrm{m}^{2} /$ day and $12.2 \mathrm{kWh} / \mathrm{m}^{2}$ / day (solar beam radiation) or between $8140 \mathrm{~L} / \mathrm{h}$ and $8260 \mathrm{~L} / \mathrm{h}$

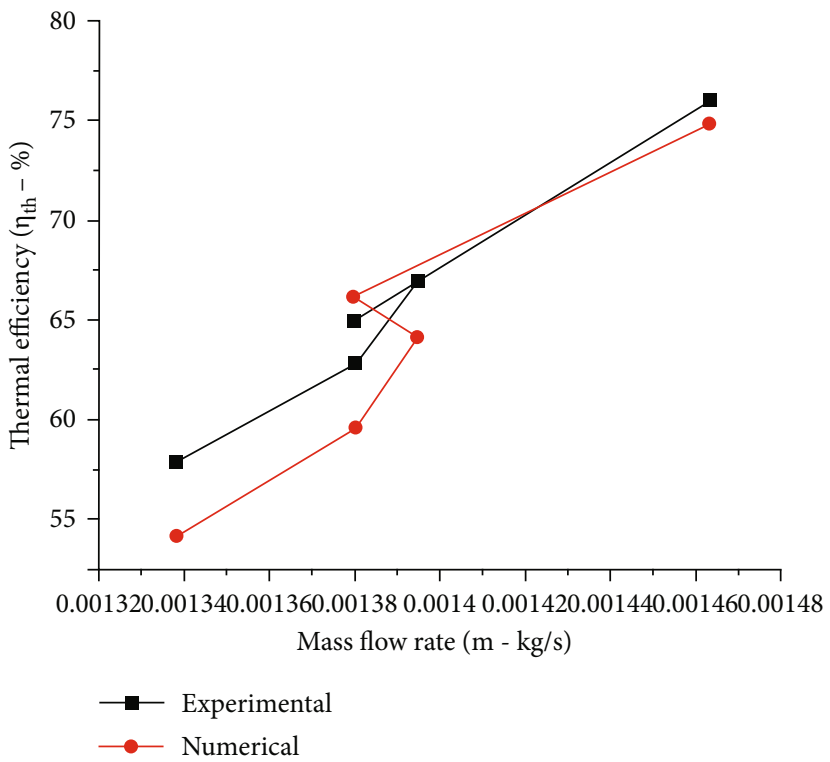

Figure 18: Comparative behavior of experimental and numerical thermal efficiency of the system with mass flow rate.

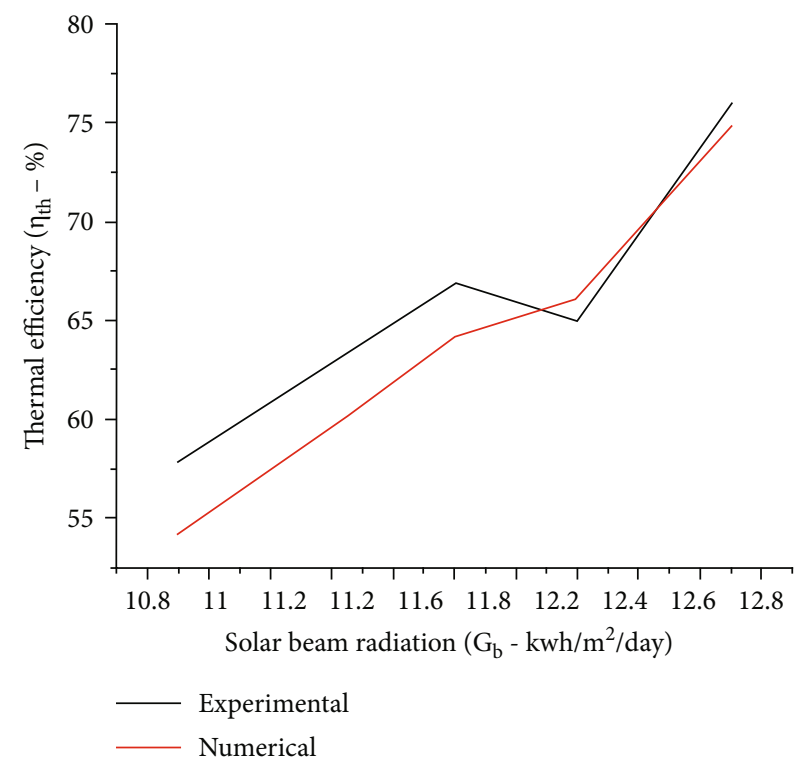

FIgURE 19: Changes in experimental and numerical values of thermal efficiency with solar beam radiation. 


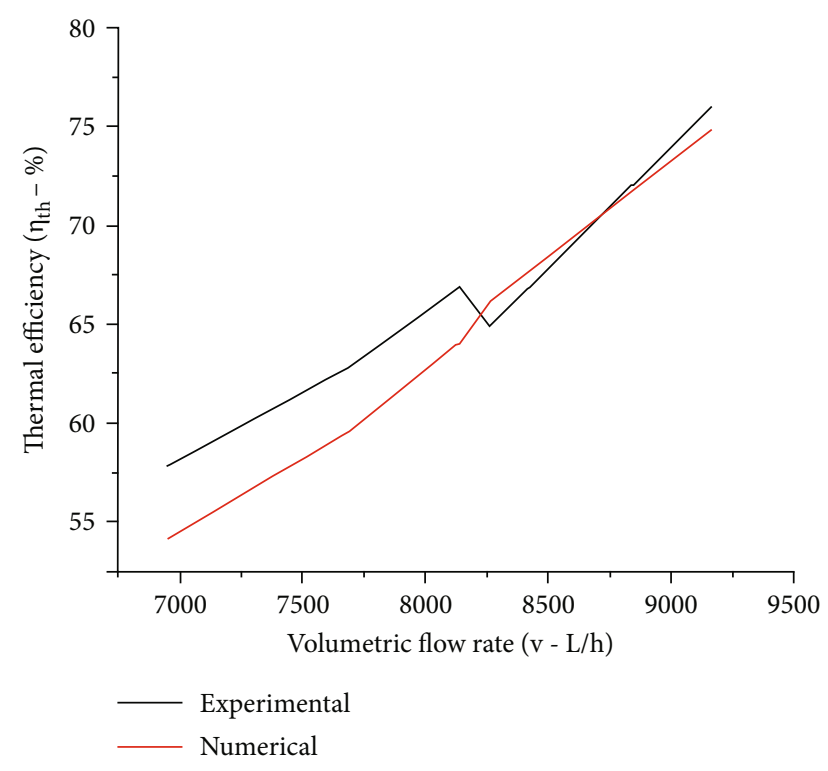

FIgURE 20: Changes in experimental and numerical values of thermal efficiency with volumetric flow rate.

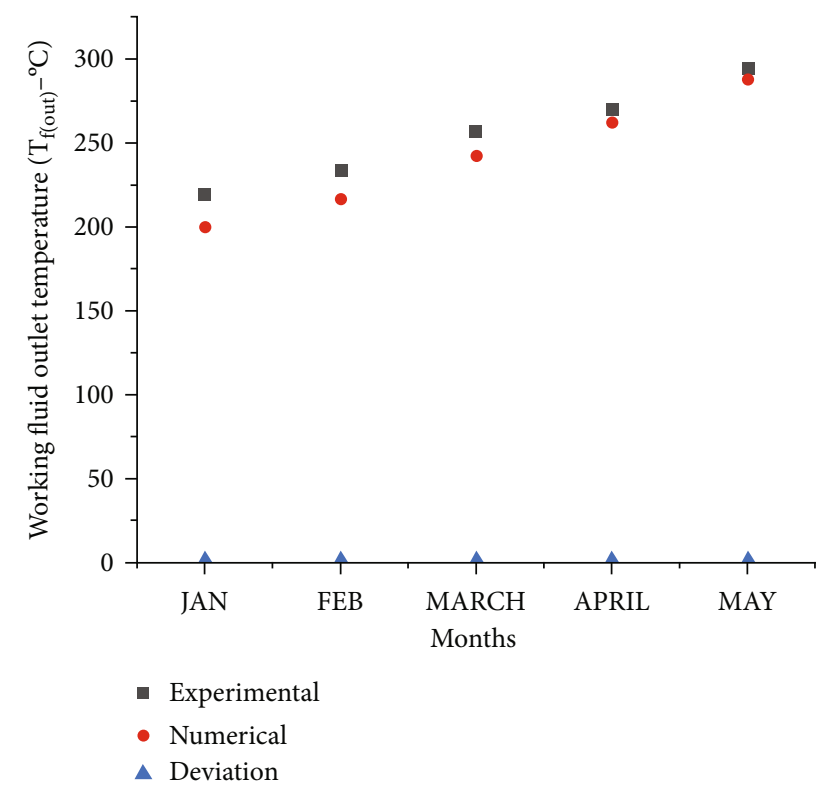

FIGURE 21: Deviation between experimental and numerical values of working fluid outlet temperature during January to May.

(volumetric flow rate), thermal efficiency reduces drastically due to inherent thermal properties of the working fluid.

As observed from Figures 21, 22, and 23, the deviation between experimental and numerical results of the SPDC system is that having a modified absorber was going to reduce from January to May. For May, it was very less. These less deviations' values validate the experimental results with the numerical results.

For the optimized performance of the SPDC system, absorber temperature and working fluid temperature at the exit of the absorber are the deciding factors. Maximum

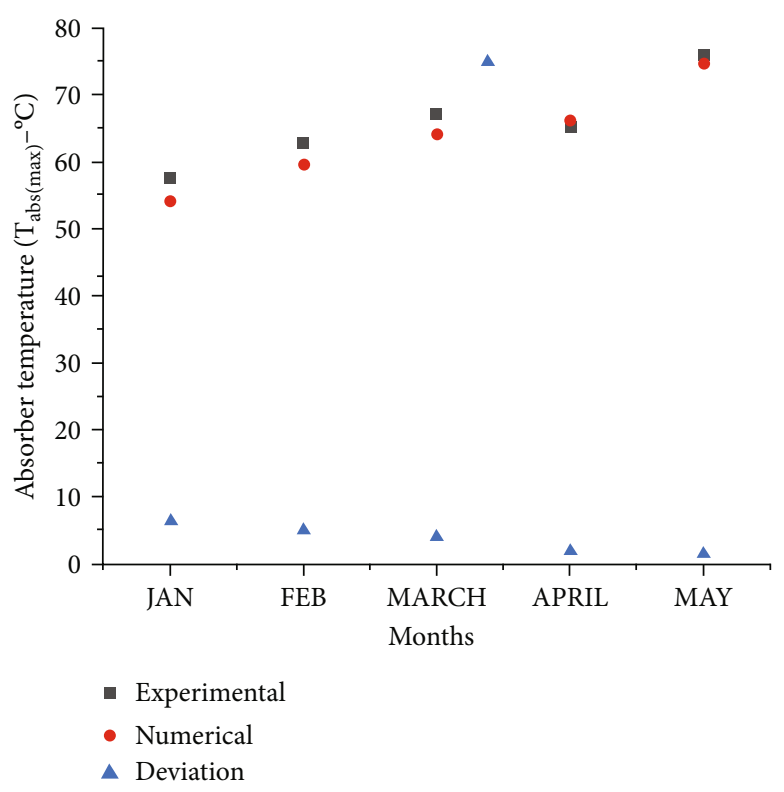

FIgURE 22: Deviation between experimental and numerical values of thermal efficiency during January to May.

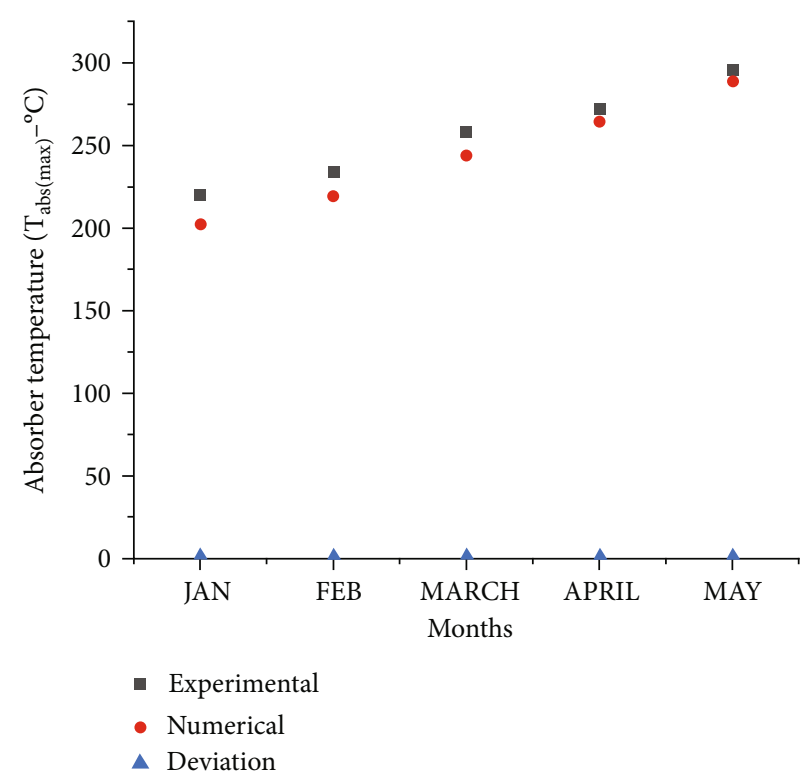

FIgURE 23: Deviation between experimental and numerical values of absorber temperature from January to May.

values of these two factors give maximum thermal efficiency of the system.

Comparative performance analysis of present and existing work is presented in Table 6. Researchers often focused on improving the thermal performance of the system by choosing different working fluid, absorber material, and improving absorber geometry. No one emphasizes on convolution effects on thermal performance. Present work emphasizes on improving thermal performance by reducing absorber size using convolution strategy. The superiority of this work is to use only 5 convolutions of spiral coil tubular 


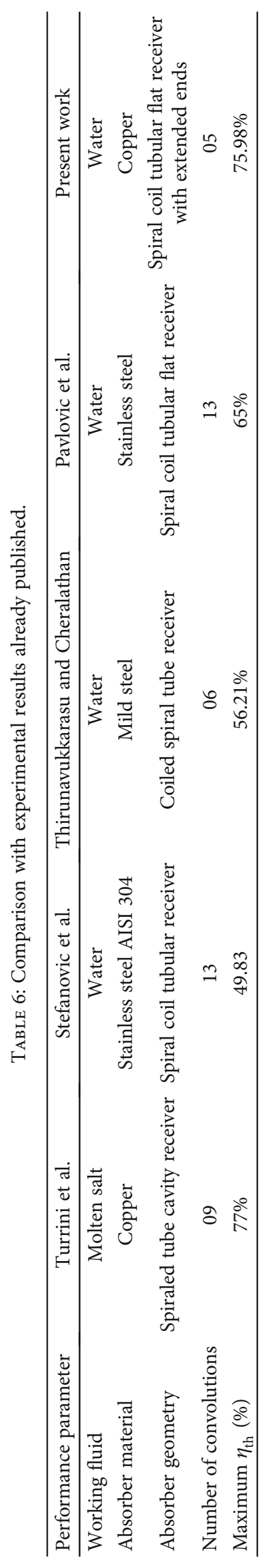


absorber with extended ends. Very less number of convolutions is found to achieve optimum performance of the modified absorber.

\section{Conclusions and Recommendations}

This work is a thermal and dynamic analysis of the utilization of a spiral coil tubular copper absorber on an SPDC. The spiral coil tubular copper absorber is appropriately designed to establish the most efficient substitute for the SPDC system. The system is first designed using a convolution strategy and then tested for different parameters with water as HTWF. The most valuable and vital concluding points of this innovative design of modified absorber are summarized as follows:

(i) Higher thermal efficiency for spiral coil tubular design leads to all the examined systems. It proves the need for the use of a spiral coil tubular copper absorber

(ii) Thermal efficiency was found the highest (i.e., $\eta_{\text {th }}$ $(\max )=75.98 \%)$ for May, and the mean thermal efficiency was found to be $\eta_{\text {th }}$ (mean) $=65.72 \%$

(iii) Numerical thermal efficiency for May and the mean value of this thermal efficiency are $74.86 \%$ and $63.80 \%$, respectively, which validates with experimental results

(iv) The maximum absorber temperature and the maximum working fluid outlet temperature are about $296^{\circ} \mathrm{C}$ and $294.2^{\circ} \mathrm{C}$, respectively, for May. This fact optimized the thermal efficiency of the modified spiral absorber

(v) The velocity of the working fluid is also increasing in order inside the absorber

(vi) Pumping pressure at the inlet of the absorber and the inlet of the steam inlet chamber coming out is $146 \mathrm{kPa}$ and $142 \mathrm{kPa}$, respectively, and approximately equal to simulating one $150.1 \mathrm{kPa}$ and $150 \mathrm{kPa}$, respectively

(vii) Improved working fluid flow characteristics resulting in less loss to turbulence

This optimized system geometry is to suit global location and season. The outputs from simulation and testing meet the solar thermal water pump system's demands for irrigation, heating, and drying applications and thermal process industries. follows:

The recommendations for future work in this area are as

(1) Optical analysis of this system in order to achieve the most optimal position of the absorber is recommended

(2) In order to reduce the cost of a concentrator, absorber material should be cheaper with efficient working. In place of copper, it could be other material or combination of materials

(3) The system is optimized for the use of water as the working fluid, although n-Pentane is the most suitable of those fluids studied. The flammability of nPentane could be hazardous if not handled correctly or if the system leaked near any source of ignition. This may make the system undesirable to certain markets. Water does however have many properties in its favour for this application. It is the researcher's opinion that this issue is only of minor concern and that it should not prevent continuing research into the system

(4) Preheating of working fluid enables it in performing efficiently, and it prevents absorber from hot-cold jerks which come from uneven heating at somehow extent

(5) Innovate the device or something for storing the solar energy so that system can be operated in rainy and cloudy days

\section{Nomenclature}

\section{Alphabetical Symbols}

A: $\quad$ Area, $\mathrm{m}^{2}$

a: $\quad$ Constant

$C_{\mathrm{p}}$ : $\quad$ Specific heat of working fluid at constant pressure,

$\mathrm{kJ} / \mathrm{kg} \mathrm{K}$

$d: \quad$ Diameter, $\mathrm{m}$

$f: \quad$ Friction factor

fr: $\quad$ Friction factor between wall of receiver and working fluid

$G_{\mathrm{b}}$ : $\quad$ Solar beam radiation, $\mathrm{kwh} / \mathrm{m}^{2} /$ day

$h$ : $\quad$ Coefficient of heat transfer, $\mathrm{W} / \mathrm{m}^{2} \mathrm{~K}$

$h_{\mathrm{e}}$ : $\quad$ Specific enthalpy, $\mathrm{kJ} / \mathrm{kg}$

I: $\quad$ Intensity of solar irradiation, $\mathrm{W} / \mathrm{m}^{2}$

$k$ : $\quad$ Thermal conductivity, $\mathrm{W} / \mathrm{mK}$

$L: \quad$ Tube length from entry to exit

$m$ : $\quad$ Mass flow rate, $\mathrm{kg} / \mathrm{s}$

$M_{x}$ : $\quad$ Degree of momentum shifting

T: $\quad$ Temperature, ${ }^{\circ} \mathrm{C}$

$T_{\mathrm{fm}}$ : $\quad$ Mean temperature of the working fluid flowing inside the receiver, ${ }^{\circ} \mathrm{C}$

$\Delta P: \quad$ Pressure difference between entry level and exit level, $\mathrm{kPa}$

Pr: $\quad$ Prandtl number

$Q_{\mathrm{u}}: \quad$ Useful energy generated, $\mathrm{kW}$

$Q_{s}$ : $\quad$ Available solar irradiation on dish aperture, $\mathrm{kW} / \mathrm{m}^{2}$

$Q_{\mathrm{rad}}: \quad$ Radiation heat transfer losses, $\mathrm{kW} / \mathrm{m}^{2}$

$Q_{\text {conv,in }}$ : Convective heat transfer losses inside the spiral coil tubular receiver, $\mathrm{kW} / \mathrm{m}^{2}$

$Q_{\text {conv,ex }}$ : Convective heat transfer losses outside the spiral coil tubular receiver, $\mathrm{kW} / \mathrm{m}^{2}$

$r$ : Radius, $m$

Re: Reynolds number 


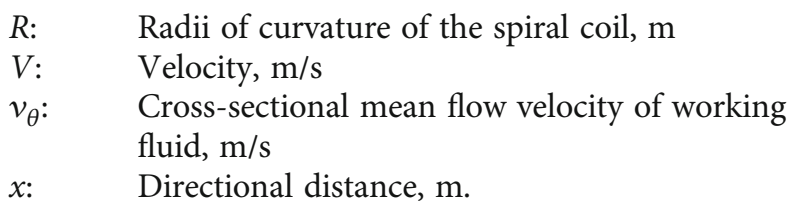

Subscripts

a: Aperture

abs: Absorber/receiver

cr: Critical

f: Working fluid

h: Hydraulic

i: Infinitesimal/inner

in: Inlet/entry

max: Maximum

o: $\quad$ Outer

opts: Optical solar

out: Outlet/exit

rec: Receiver/absorber

s: $\quad$ Surface

th: Thermal.

\section{Abbreviations}

CPC: Compound parabolic collector

CR: Concentration ratio

HTC: Heat transfer characteristics

HTWF: Heat transfer working fluid

PD: Parabolic dish

PTC: Parabolic trough collector

SPDC: Solar parabolic dish concentrator/collector.

\section{Greek Symbols}

$\theta$ : Total rotational angle

$\eta$ : Efficiency

$\rho$ : Fluid density, $\mathrm{kg} / \mathrm{L}$

$v$ : Volumetric flow rate, $\mathrm{L} / \mathrm{h}$

$\gamma$ : Intercept factor.

\section{Data Availability}

The data used to support the findings of this study are included within the article. These data were found experimentally, and no other specific data were used to support this study.

\section{Conflicts of Interest}

The authors declare that they have no known competing financial interests or personal relationships that could have appeared to influence the work reported in this paper.

\section{Authors' Contributions}

Rajkumar Malviya performed the methodology, wrote the original draft, and performed the investigation. Anil Kumar participated in the conceptualization, visualization, writing, reviewing, and editing of the manuscript, and supervision. Prashant V. Baredar did the supervision.

\section{Acknowledgments}

The first author would like to thank Maulana Azad National Institute of Technology, Bhopal (India), for awarding the fellowship for pursuing the Ph.D. in the Energy Centre and gratefully acknowledge the Centre for Energy and Environment, Delhi Technological University, Delhi, for the support to the present work.

\section{References}

[1] K. S. Reddy and N. Sendhil Kumar, "Combined laminar natural convection and surface radiation heat transfer in a modified cavity receiver of solar parabolic dish," International Journal of Thermal Sciences, vol. 47, no. 12, pp. 1647-1657, 2008.

[2] A. M. Daabo, S. Mahmoud, and R. K. Al-Dadah, "The optical efficiency of three different geometries of a small scale cavity receiver for concentrated solar applications," Applied Energy, vol. 179, pp. 1081-1096, 2016.

[3] S. Pavlovic, R. Loni, E. Bellos, D. Vasiljević, G. Najafi, and A. Kasaeian, "Comparative study of spiral and conical cavity receivers for a solar dish collector," Energy Conversion and Management, vol. 178, pp. 111-122, 2018.

[4] E. Bellos, E. Bousi, C. Tzivanidis, and S. Pavlovic, "Optical and thermal analysis of different cavity receiver designs for solar dish concentrators," Energy Convers Manag X, vol. 2, p. 100013, 2019.

[5] S. Pavlovic, A. M. Daabo, E. Bellos, V. Stefanovic, S. Mahmoud, and R. K. Al-Dadah, "Experimental and numerical investigation on the optical and thermal performance of solar parabolic dish and corrugated spiral cavity receiver," Journal of Cleaner Production, vol. 150, pp. 75-92, 2017.

[6] S. Chu, F. Bai, X. Zhang, B. Yang, Z. Cui, and F. Nie, "Experimental study and thermal analysis of a tubular pressurized air receiver," Renewable Energy, vol. 125, pp. 413-424, 2018.

[7] S. Turrini, M. Bettonte, M. Eccher, M. Grigiante, A. Miotello, and R. S. Brusa, "An innovative small-scale prototype plant integrating a solar dish concentrator with a molten salt storage system," Renewable Energy, vol. 123, pp. 150-161, 2018.

[8] V. P. Stefanovic, S. R. Pavlovic, E. Bellos, and C. Tzivanidis, “A detailed parametric analysis of a solar dish collector," Sustainable Energy Technologies and Assessments, vol. 25, pp. 99-110, 2018.

[9] H. Cherif, A. Ghomrassi, J. Sghaier, H. Mhiri, and P. Bournot, "A receiver geometrical details effect on a solar parabolic dish collector performance," Energy Reports, vol. 5, pp. 882-897, 2019.

[10] K. L. Lee, M. Jafarian, F. Ghanadi, M. Arjomandi, and G. J. Nathan, "An investigation into the effect of aspect ratio on the heat loss from a solar cavity receiver," Solar Energy, vol. 149, pp. 20-31, 2017.

[11] S. Yang, J. Wang, P. D. Lund, S. Wang, and C. Jiang, "Reducing convective heat losses in solar dish cavity receivers through a modified air-curtain system," Solar Energy, vol. 166, pp. 5058, 2018.

[12] M. Tian, Y. Su, H. Zheng, G. Pei, G. Li, and S. Riffat, "A review on the recent research progress in the compound parabolic concentrator (CPC) for solar energy applications," 
Renewable and Sustainable Energy Reviews, vol. 82, pp. 1272-1296, 2018.

[13] R. Loni, E. Askari Asli-Ardeh, B. Ghobadian, E. Bellos, and W. G. le Roux, "Numerical comparison of a solar dish concentrator with different cavity receivers and working fluids," Journal of Cleaner Production, vol. 198, pp. 1013-1030, 2018.

[14] R. Loni, A. B. Kasaeian, E. Askari Asli-Ardeh, B. Ghobadian, and S. Gorjian, "Experimental and numerical study on dish concentrator with cubical and cylindrical cavity receivers using thermal oil," Energy, vol. 154, pp. 168-181, 2018.

[15] W. Fuqiang, C. Ziming, T. Jianyu, Y. Yuan, S. Yong, and L. Linhua, "Progress in concentrated solar power technology with parabolic trough collector system: a comprehensive review," Renewable and Sustainable Energy Reviews, vol. 79, pp. 1314-1328, 2017.

[16] E. Bellos, C. Tzivanidis, and K. A. Antonopoulos, “A detailed working fluid investigation for solar parabolic trough collectors," Applied Thermal Engineering, vol. 114, pp. 374-386, 2017.

[17] B. Zou, Y. Jiang, Y. Yao, and H. Yang, "Thermal performance improvement using unilateral spiral ribbed absorber tube for parabolic trough solar collector," Solar Energy, vol. 183, pp. 371-385, 2019.

[18] M. Bahrami, V. Madadi Avargani, and M. Bonyadi, "Comprehensive experimental and theoretical study of a novel still coupled to a solar dish concentrator," Applied Thermal Engineering, vol. 151, pp. 77-89, 2019.

[19] M. Ali, M. Rady, M. A. A. Attia, and E. M. Ewais, "Consistent coupled optical and thermal analysis of volumetric solar receivers with honeycomb absorbers," Renewable Energy, vol. 145, pp. 1849-1861, 2020.

[20] Q. Li, C. Zheng, S. Mesgari et al., "Experimental and numerical investigation of volumetric versus surface solar absorbers for a concentrated solar thermal collector," Solar Energy, vol. 136, pp. 349-364, 2016.

[21] A. B. Auti, D. R. Pangavane, T. P. Singh, and M. Sapre, "Estimation of time of tracking for designed absorber used in domestic solar desalination system using experimental and finite element analysis (ANSYS)," Materials Today: Proceedings, vol. 4, no. 2, pp. 2516-2524, 2017.

[22] J. Satpute, K. Chavan, and N. Gulhane, "Thermal performance investigation of concentrated solar collector using novel aluminum absorber," Materials Today: Proceedings, vol. 5, no. 2, pp. 4059-4065, 2018.

[23] W. Wang and B. Laumert, "Effect of cavity surface material on the concentrated solar flux distribution for an impinging receiver," Solar Energy Materials \& Solar Cells, vol. 161, pp. 177-182, 2017.

[24] F. Wang, Y. Shuai, H. Tan, X. Zhang, and Q. Mao, "Heat transfer analyses of porous media receiver with multi-dish collector by coupling MCRT and FVM method," Solar Energy, vol. 93, pp. 158-168, 2013.

[25] S. Pavlovic R., E. Bellos, V. Stefanovic P., C. Tzivanidis, and Z. Stamenkovic M., "Design, simulation, and optimization of a solar dish collector with spiral-coil thermal absorber," Thermal Science, vol. 20, no. 4, pp. 1387-1397, 2016.

[26] R. Figaj, M. Szubel, E. Przenzak, and M. Filipowicz, "Feasibility of a small-scale hybrid dish/flat-plate solar collector system as a heat source for an absorption cooling unit," Applied Thermal Engineering, vol. 163, p. 114399, 2019.
[27] C. Zou, Y. Zhang, H. Feng et al., "Effects of geometric parameters on thermal performance for a cylindrical solar receiver using a 3D numerical model," Energy Conversion and Management, vol. 149, pp. 293-302, 2017.

[28] J. P. Bijarniya, K. Sudhakar, and P. Baredar, "Concentrated solar power technology in India: a review," Renewable and Sustainable Energy Reviews, vol. 63, pp. 593-603, 2016.

[29] V. Thirunavukkarasu and M. Cheralathan, "An experimental study on energy and exergy performance of a spiral tube receiver for solar parabolic dish concentrator," Energy, vol. 192, p. 116635, 2020.

[30] F. V. Barbosa, J. L. Afonso, F. B. Rodrigues, and J. C. F. Teixeira, "Development of a solar concentrator with tracking system," The journal Mechanical Sciences, vol. 7, no. 2, pp. 233-245, 2016.

[31] O. R. Sandoval, B. C. Caetano, M. U. Borges, J. J. García, and R. M. Valle, "Modelling, simulation and thermal analysis of a solar dish/Stirling system: a case study in Natal, Brazil," Energy Conversion and Management, vol. 181, pp. 189-201, 2019.

[32] S. Soltani, M. Bonyadi, and V. Madadi Avargani, "A novel optical-thermal modeling of a parabolic dish collector with a helically baffled cylindrical cavity receiver," Energy, vol. 168, pp. 88-98, 2019.

[33] R. Affandi, A. Ghani, C. K. Ghan, and L. G. Pheng, "The impact of the solar irradiation, collector and the receiver to the receiver losses in parabolic dish system," Procedia - Social and Behavioral Sciences, vol. 195, pp. 2382-2390, 2015.

[34] Y. O. O. Geun-jong, C. Hoon-ki, and D. Wa-ryong, "Fluid flow and heat transfer characteristics of spiral coiled tube : effects of Reynolds number and curvature ratio Fluid flow and heat transfer characteristics of spiral coiled tube : effects of Reynolds number and curvature ratio," 2014.

[35] R. Karimi, T. T. Gheinani, and V. Madadi Avargani, "A detailed mathematical model for thermal performance analysis of a cylindrical cavity receiver in a solar parabolic dish collector system," Renewable Energy, vol. 125, pp. 768-782, 2018.

[36] R. Loni, A. B. Kasaeian, O. Mahian, and A. Z. Sahin, "Thermodynamic analysis of an organic rankine cycle using a tubular solar cavity receiver," Energy Conversion and Management, vol. 127, pp. 494-503, 2016.

[37] S. A. Kalogirou, S. Karellas, K. Braimakis, C. Stanciu, and V. Badescu, "Exergy analysis of solar thermal collectors and processes," Progress in Energy and Combustion Science, vol. 56, pp. 106-137, 2016.

[38] X.-L. Li, X.-L. Xia, Z.-H. Li, and X. Chen, "Effects of double windows on optical and thermal performance of solar receivers under concentrated irradiation," Solar Energy, vol. 184, pp. 331-344, 2019.

[39] S. Skouri, S. Bouadila, M. Ben Salah, and S. Ben Nasrallah, "Comparative study of different means of concentrated solar flux measurement of solar parabolic dish," Energy Conversion and Management, vol. 76, pp. 1043-1052, 2013.

[40] T. Maatallah and W. B. Youssef, "Simulation and performance analysis of concentrating photovoltaic/thermal collector $(\mathrm{CPV} / \mathrm{T})$ with three-sided thermal insulation based on coupled optothermal model," Solar Energy, vol. 181, pp. 308-324, 2019.

[41] G. Barreto and P. Canhoto, "Modelling of a Stirling engine with parabolic dish for thermal to electric conversion of solar 
energy," Energy Conversion and Management, vol. 132, pp. 119-135, 2017.

[42] C. Zou, Y. Zhang, Q. Falcoz et al., "Design and optimization of a high-temperature cavity receiver for a solar energy cascade utilization system," Renewable Energy, vol. 103, pp. 478-489, 2017.

[43] M. Hatami, J. Geng, and D. Jing, "Enhanced efficiency in concentrated parabolic solar collector (CPSC) with a porous absorber tube filled with metal nanoparticle suspension," Green Energy \& Environment, vol. 3, no. 2, pp. 129-137, 2018. 